\title{
forence
}

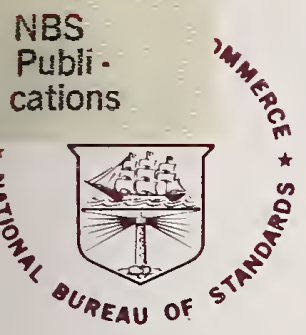

NBS TECHNICAL NOTE 913

U.S. DEPARTMENT OF COMMERCE / National Bureau of Standards

\section{Modification of an NBS Reference Spectrophotometer}




\section{NATIONAL BUREAU OF STANDARDS}

The National Bureau of Standards ${ }^{1}$ was established by an act of Congress March 3, 1901. The Bureau's overall goal is to strengthen and advance the Nation's science and technology and facilitate their effective application for public benefit. To this end, the Bureau conducts research and provides: (1) a basis for the Nation's physical measurement system, (2) scientific and technological services for industry and government, (3) a technical basis for equity in trade, and (4) technical services to promote public safety. The Bureau consists of the Institute for Basic Standards, the Institute for Materials Research, the Institute for Applied Technology, the Institute for Computer Sciences and Technology, and the Office for Information Programs.

THE INSTITUTE FOR BASIC STANDARDS provides the central basis within the United States of a complete and consistent system of physical measurement; coordinates that system with measurement systems of other nations; and furnishes essential services leading to accurate and uniform physical measurements throughout the Nation's scientific community, industry, and commerce. The Institute consists of the Office of Measurement Services, the Office of Radiation Measurement and the following Center and divisions:

Applied Mathematics - Electricity - Mechanics - Heat - Optical Physics - Center for Radiation Research: Nuclear Sciences; Applied Radiation - Laboratory Astrophysics ${ }^{2}$ - Cryogenics ${ }^{2}$ - Electromagnetics ${ }^{2}$ - Time and Frequency ${ }^{2}$.

THE INSTITUTE FOR MATERIALS RESEARCH conducts materials research leading to improved methods of measurement, standards, and data on the properties of well-characterized materials needed by industry, commerce, educational institutions, and Government; provides advisory and research services to other Government agencies; and develops, produces, and distributes standard reference materials. The Institute consists of the Office of Standard Reference Materials, the Office of Air and Water Measurement, and the following divisions:

Analytical Chemistry - Polymers - Metallurgy - Inorganic Materials - Reactor Radiation - Physical Chemistry.

THE INSTITUTE FOR APPLIED TECHNOLOGY provides technical services to promote the use of available technology and to facilitate technological innovation in industry and Government; cooperates with public and private organizations leading to the development of technological standards (including mandatory safety standards), codes and methods of test; and provides technical advice and services to Government agencies upon request. The Institute consists of the following divisions and Centers:

Standards Application and Analysis - Electronic Technology - Center for Consumer Product Technology: Product Systems Analysis; Product Engineering - Center for Building Technology: Structures, Materials, and Life Safety; Building Environment; Technical Evaluation and Application - Center for Fire Research: Fire Science; Fire Safety Engineering.

THE INSTITUTE FOR COMPUTER SCIENCES AND TECHNOLOGY conducts research and provides technical services designed to aid Government agencies in improving cost effectiveness in the conduct of their programs through the selection, acquisition, and effective utilization of automatic data processing equipment; and serves as the principal focus within the executive branch for the development of Federal standards for automatic data processing equipment, techniques, and computer languages. The Institute consists of the following divisions:

Computer Services - Systems and Software - Computer Systems Engineering - Information Technology.

THE OFFICE FOR INFORMATION PROGRAMS promotes optimum dissemination and accessibility of scientific information generated within NBS and other agencies of the Federal Government; promotes the development of the National Standard Reference Data System and a system of information analysis centers dealing with the broader aspects of the National Measurement System; provides appropriate services to ensure that the NBS staff has optimum accessibility to the scientific information of the world. The Office consists of the following organizational units:

Office of Standard Reference Data - Office of Information Activities - Office of Technical Publications - Library - Office of International Relations - Office of International Standards.

1 Headquarters and Laboratories at Gaithersburg, Maryland, unless otherwise noted; mailing address Washington, D.C. 20234

Located at Boulder, Colorado 80302 . 


\section{Modification of an NBS Reference Spectrophotometer}

\section{t. Technical Vote no. 913}

Kenneth L. Eckerle

Institute for Basic Standards

National Bureau of Standards

Washington, D.C. 20234

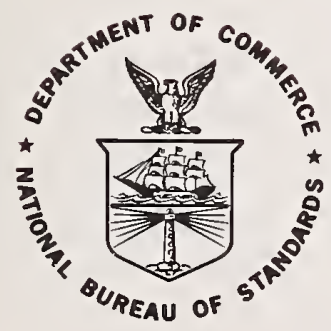

U.S. DEPARTMENTT OF COMMERCE, Elliot L. Richardson, Secretary

Dr. Betsy Ancker-Johnson, Assistant Secretary for Science and Technology

US NATIONAL BUREAU OF STANDARDS, Ernest Ambler, Acting Director

Issued July 1976 
National Bureau of Standards Technical Note 913

Nat. Bur. Stand. (U.S.), Tech. Note 913, 43 pages (July 1976)

CODEN: NBTNAE 


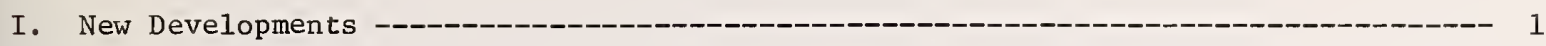

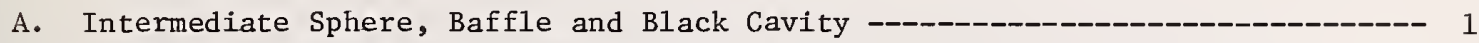

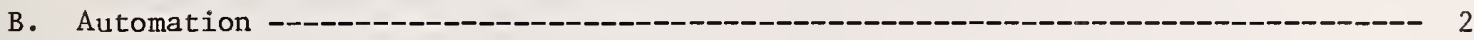

1. Wavelength Scale ------------ 2

2. Light Level Adjustment and Polarization Adjustment ----------------------- 2

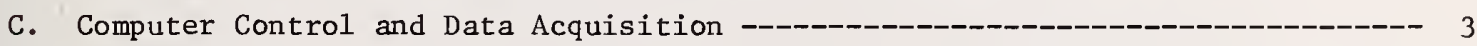

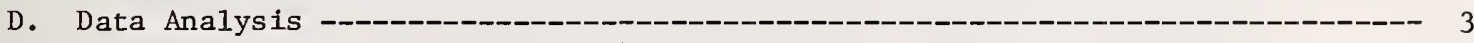

1. Method A --_---_--- 3

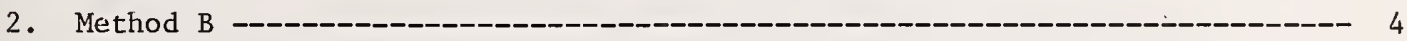

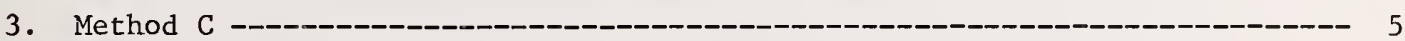

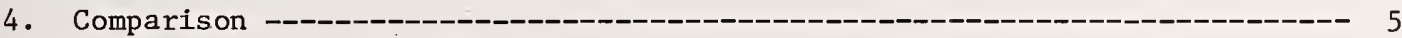

5. Equal and Unequal Time Intervals --_---_---_--- 5

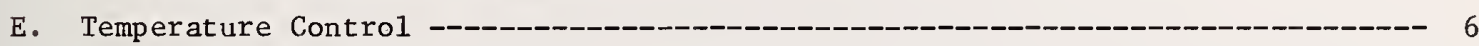

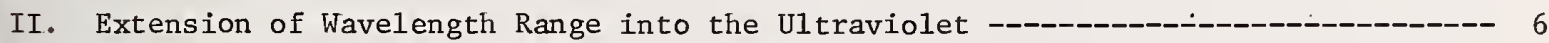

A. New Optics - 6

B. Sources --

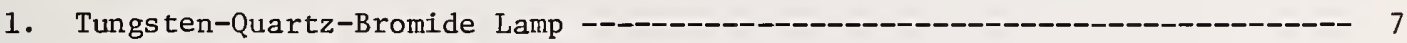

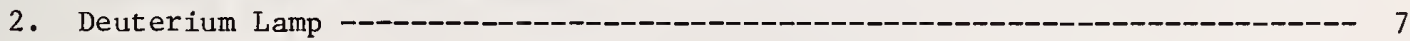

C. Fluorocarbon Coated Sphere with Efficient Design ---------------------------- 7

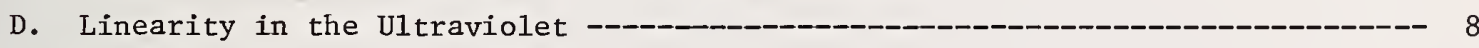

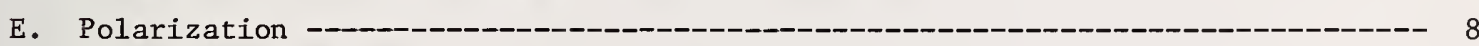

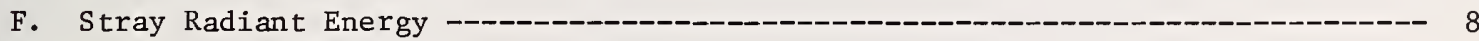

G. Actual Measurements -_-

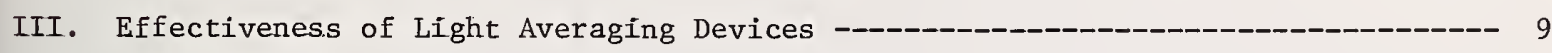

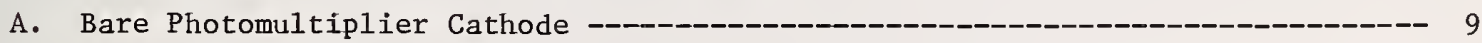

B. Intermediate Sphere Used for Visible Spectrum ----------------------- 10

C. Fluorocarbon Coated Sphere with Efficient Design ---------------------------- 10

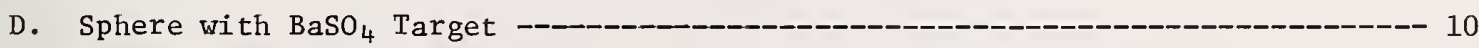

E. Sphere with Fluorescent Target --

F. UV Averager with Ground Quartz Diffusers --_- 11

G. Etched Glass -- -

H. Summary -

Appendix A. Light Collection Solid Angle for Intermediate Sphere ------------------- 12

Acknowled gments --_-_-_-_-_-_-_-_-_-_-_-_- 13

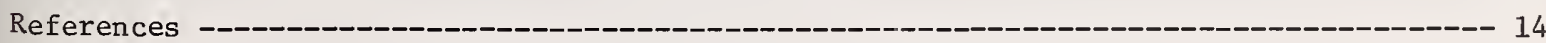



The description of a new reference spectrophotometer capable of making transmittance measurements accurate to 0.0001 transmittance units has already been reported. The purpose of this publication is to describe some modifications that have been made to this instrument and to report some further measurements performed with it. The extension of the range of the instrument down to $200 \mathrm{~nm}$, providing a capability for making measurements over the spectral range 200 to $800 \mathrm{~nm}$, is outlined, and extensive testing of the light averaging effectiveness of several types ò devices and spheres is reported here.

Key Words: Averaging spheres; high accuracy transmittance; light averaging devices; linearity; photometric precision; reference spectrophotometer; ultraviolet; wavelength calibration.

\section{New Developments}

The present configuration of the new reference spectrophotometer capable of making measurements with an accuracy of 0.0001 transmittance units is shown by the schematic drawing in Figure 1. The primary modifications from the previously published configuration [1] ${ }^{1}$ and [2] are a change in source optics, the elimination of two mirrors in front of the averaging sphere, the installation of new averaging spheres (as requirements arose), additional changes to extend the range of the instrument into the ultraviolet spectral region, further automation, and a provision for temperature control of samples. These features will be discussed in detail below.

A number of special tests and calibrations have been made using the new reference spectrophotometer. These measurements provide a basis for prediction of the precision of the instrument in the visible spectral range. The standard error of the random fluctuations in a set of four representative transmittance measurements is shown in Figure 2 as a function of transmittance of the sample. The values shown will be correct to within a factor of 2 depending upon the photomultiplier voltage used and the light level.

The linearity of the photomultiplier and electronics has been monitored over a period of several years. No significant change in linearity has been observed. The results of some of the measurements of the linearity correction at $525 \mathrm{~nm}$ are listed in Table I where the correct transmittance equals the measured transmittance plus $\Delta \mathrm{T}$.

\section{A. Intermediate Sphere, Baffle and Black Cavity}

Extension of the range of the spectrophotometer into the ultraviolet required development of a new sphere design using coatings that have newly become available. Such a sphere, which also performs well in the visible wavelength range, is discussed in Section II below. However, before extension into the ultraviolet, an intermediate sphere design was found necessary in the visible wavelength range.

Several special tests performed with the reference spectrophotometer required a welldefined solid angle of collection at the detection system. These tests included measurements of transmittance of scattering filters and screens. The original sphere design featured an off-axis parabolic mirror that collected the light after it passed through the sample and focused the light on a small sphere opening after deflection from a flat mirror. Calculations showed that the parabola-flat combination provided an ill-defined limiting

\footnotetext{
${ }^{1}$ Figures in brackets indicate the literature references on page 14.
} 
aperture, and one could not accurately predict the solid angle of acceptance. The foundation for a mathematical formalism of this problem is given in Ref. [3].

A new design was formulated that eliminated the collecting parabola and flat mirror. This design features a $150 \mathrm{~mm}$ diameter sphere of similar design as before, but the sphere has a $30 \mathrm{~mm}$ diameter opening cut on a circular cylinder parallel to the plane defined by the photomultiplier cathode as in Figure 3. This necessitated moving the photomultiplier further from the sphere so that no first reflections from the sphere wall fall on the cathode. These two changes decrease the efficiency of the detection system by about a factor of 2 to approximately 10\%. A derivation of the equation for calculating the efficiency of this type of sphere is given in Ref. [4]. Also in this reference, it is shown how to obtain a marked improvement in efficiency by adding a reflecting "collar" between sphere and photocathode without loss in averaging effectiveness. Since the sphere now views almost the whole interior of the light tight box (which is sheet metal painted with flat black paint), it was necessary to introduce two $73 \mathrm{~mm}$ diameter baffles with two openings $50 \mathrm{~mm}$ in diameter enclosed in a tube $150 \mathrm{~mm}$ long.

The new sphere design required that a pneumatically controlled cavity which slides into and out of the beam and which was lined with black velvet be used for the "zero" measurements so that no light is reflected around and into the sphere. A baffle at the entrance port of the sphere was found necessary. Also, care is taken so that the specularly reflected light from a sample is trapped either by the monochromator for normal incidence or by a cavity if the angle of incidence is different from normal.

The solid angle of acceptance for this system is well defined as the calculation in Appendix A shows; and if the goniophotometric distribution of scattered light or diffracted light from the sample is known, corrections may be applied. By measuring the transmittance at different sample-to-sphere distances, the presence of scattering can be detected, and its magnitude estimated.

\section{B. Automation}

A limited amount of automation had previously been done with reference spectrophotometer [1] and [2]. In order to make more extensive measurements, a sophisticated level of automation became necessary. This was accomplished by means of a "Modular Interactive Data Acquisition System" (MIDAS) with a teletypewriter and mini-computer, as described in Ref. [5]. In order to automate, we needed the following modules: two sets of eight relays, a twenty-four hour clock, an interval timer, two stepping motor controllers, and a BCD multiplexer capable of handling two inputs.

\section{Wavelength Scale}

An important step was automating the wavelength drive of the monochromator so that a measurement could automatically be made at successive wavelengths, each measurement taking ten to twenty minutes. This was done by coupling a stepper motor on to the wavelength drive through the existing gear train so that the drive screw would not receive undue shock. It was found that this. was accurate to $0.01 \mathrm{~nm}-$ the setting accuracy of the wavelength dial. The gears chosen for normal measurements were the ones that yielded a step size of $0.0208337 \AA$ per step of the motor.

\section{Light Level Adjustment and Polarization Adjustment}

The Glan-Thompson prism nearest the monochromator in Figure 1 provides a well-defined polarization of light. The other prism may be rotated to provide variable attenuation of the light beam. Thus, desired signal levels can be obtained and still keep the lamp current and the photomultiplier voltage fixed throughout an experiment. Both Glan-Thompson prisms were mounted in polar rotation modules to which a stepper motor had been coupled. Thus, the state of polarization of the light could be changed automatically by means of the MIDAS system. Also, a feedback circuit was attached to the clockwise-counterclockwise control of the attenuating prism.

The purpose of the feedback circuit is to adjust the attenuating prism to produce a predetermined signal $(1.0,0.8,0.6,0.4$, and 0.2 of full scale reading). The predetermined level can be selected by means of the MIDAS system. Thus, the $100 \%$ level can be adjusted after changing wavelengths or the state of polarization, or all five levels can be utilized when making linearity measurements as described in Ref. [6]. 


\section{Computer Control and Data Acquisition}

In the first stages of the automation, the MIDAS was controlled by a program on paper tape, but as the automation was completed, the experiments became more complicated, and it was necessary to switch to an existing time-shared minicomputer for most data acquisition. However, the previous condition that the data be taken at equal time intervals was no longer satisfied since the minicomputer is time-shared and one cannot depend on it to respond instantaneously. To overcome this difficulty, we used the answer back drum on the teletypewriter to record the exact time a reading was initiated, and analyzed the data as described in the next section.

\section{Data Analysis}

One, two or three filters may be measured in the same run by use of an existing filter wheel. The method for three filters will, be outlined here. The sequence for a three filter measurement is

$$
, I_{0}, I_{1}, I_{2}, I_{3}, I_{0}, I_{3}, I_{2}, I_{1}, I_{0}, I_{1}, I_{2}, I_{3}, I_{0}, I_{3}, I_{2}, I_{1}, I_{0},
$$

where $I_{0}$ is the clear space signal and $I_{1}, I_{2}, I_{3}$ are the signals for the three filters, and the commas denote the dark space or "zero" reading. It will be assumed that the zero measurements (which are interpolated) are subtracted from the clear space or filter signals before any further analysis is performed. If $i$ denotes the signal for clear space or for a given filter and $j$ denotes the reading for a given $i$, (total number, $N_{j}$ ); then since the drift is approximately linear, the predicted value for the measurements, $I_{i j}$, will be

$$
I_{i j}^{\prime}=\left(\bar{m} t_{i j}+1\right) I_{o i}
$$

where $\bar{m}$ is a constant whose magnitude determines the slope of the drift with time and where $I_{0 i}$ is the signal at time $t_{0}$ where

$$
t_{0}=\frac{t_{\text {initial }}+t_{\text {final }}}{2}
$$

and $t_{\text {initial }}$ and $t_{\text {final }}$ are the times at which the first and last measurements were made. The scaled time is

$$
t_{i j}=t-t_{0}
$$

Three methods (designated $A, B$, and $C$ ) were used to calculate $\bar{m}$ and the set of $I_{o i}$.

\section{Method $\mathrm{A}$}

This method uses normalized values in a manner similar to that which was used previously for data acquired at equal time intervals. If we let

$$
Z_{i j}^{\prime}=\frac{I_{i j}^{\prime}}{I_{o i}}=\bar{m}_{i j}+1 \equiv q_{o i} I_{i j}^{\prime}
$$

the variance of $z_{i j}$ is

$$
\begin{array}{r}
\delta^{2}=\sum_{i}\left(\frac{1}{N_{i}-2}\right) \sum_{j}\left(z_{i j}^{\prime}-z_{i j}\right)^{2} \\
=\sum_{i}\left(\frac{1}{N_{i}-2}\right) \sum_{j}\left[q_{o i} I_{i j}-\left(\bar{m} t_{i j}+1\right)\right]^{2}
\end{array}
$$


Using the method of least squares to minimize $\delta^{2}$, we have

$$
\bar{m}=\frac{\sum_{i}\left(\frac{1}{N_{i}-2}\right) \sum_{j}\left(q_{o i} I_{i j} t_{i j}-t_{i j}\right)}{\sum_{i}\left(\frac{1}{N_{i}-2}\right) \sum_{j} t_{i j}^{2}}
$$

and the set of $q_{o i}$ is

$$
q_{o i}=\frac{\sum_{j}\left(\bar{m}_{i j}+1\right) I_{i j}}{\sum_{j} I_{i j}^{2}} \quad i=1,2, \ldots
$$

To find the set of $q_{o i}$ and $\vec{m}$, we first set $\bar{m}=0$ to get approximate $q_{o i}$. These $q_{o i}$ in turn give an order of magnitude for $\overline{\mathrm{m}}$. Then, an iterative procedure is used to obtain ${ }^{\mathrm{i}} \overline{\mathrm{m}}$ and $\mathrm{q}_{\mathrm{oi}}$. Then, the $\mathrm{q}_{\mathrm{oi}}$ are used to calculate the transmittance and the standard error of the predicted values $I_{i j}^{+}$. The transmittance for the $(n-1)$ th filter is

$$
\tau_{n-1}=\frac{q_{o 1}}{q_{o n}} \quad n=2,3,4
$$

and the standard error, $\mathrm{s}_{\mathrm{n}-1}$ is

$$
s_{n-1}=\tau_{n-1}\left[\left(\text { Variance }_{n}\right)\left(q_{o n}{ }^{2}\right)+\left(\text { Variance }_{1}\right)\left(q_{o 1}{ }^{2}\right)\right]^{\frac{1}{2}}
$$

where

$$
\text { Variance }_{i}=\frac{\sum_{j}\left(I_{i j}^{\prime}-I_{i j}\right)^{2}}{N_{i}\left(N_{i}-2\right)} \quad i=1,2,3,4
$$

This method was used until April, 1976 when some very low transmittances were measured without using a step-down technique where some of the $I_{i j}$ 's were zero or even negative. For these cases equation ( 8 ) fails, and it was decided to use Method B.

\section{Method B}

Using this method, the variance of the $I_{i j}$ 's are computed without normalization. The variance, $\delta^{2}$, is

$$
\begin{gathered}
\delta^{2}=\sum_{i}\left(\frac{1}{N_{i}-2}\right) \sum_{j}\left(I_{i j}^{\prime}-I_{i j}\right)^{2} \\
=\sum_{i}\left(\frac{1}{N_{i}-2}\right) \sum_{j}\left[\left(\bar{m}_{i j}+1\right) I_{o i}-I_{i j}\right]^{2}
\end{gathered}
$$

Again, using the method of least squares to minimize $\delta^{2}$ we have,

$$
\vec{m}=\frac{\sum_{i}\left(\frac{1}{N_{i}-2}\right) \sum_{j}\left(I_{i j}-I_{o i}\right) t_{i j} I_{o i}}{\sum_{i}\left(\frac{1}{N_{i}-2}\right) \sum_{j} t_{i j}^{2} I_{o i}}
$$


and the set of $I_{\text {oi }}$

$$
I_{o i}=\frac{\sum_{j}\left(\bar{m}_{i j}+1\right) I_{i j}}{\sum_{j}\left(\bar{m}_{i j}+1\right)^{2}} \quad i=1,2, \ldots
$$

The transmittances are,

$$
\tau_{n-1}=\frac{I_{\text {on }}}{I_{\text {ol }}} \quad n=2,3,4
$$

and the standard errors are

$$
S_{n-1}=\tau_{n-1}\left[\frac{\text { Variance }_{n}}{I_{o n}{ }^{2}}+\frac{\text { Variance }_{1}}{I_{o 1}{ }^{2}}\right]
$$

The solution to equations (14) and (15) were solved by iteration as in Section I-D-1.

\section{Method $\mathrm{C}$}

Still a third method was used by Dr. H. H. Ku of Applied Mathematics Division of the NBS. Taking the logarithm on both sides of equation (1), we have

$$
\ln I_{i j}=\operatorname{InI} I_{i j}^{\prime}+e_{i j}=\operatorname{In}\left(\bar{m}_{i j}+1\right)+\ln I_{o i}+e_{i j}
$$

where $e_{i j}$ are error measurements, approximately constant after the logarithm transformation. Since $\overline{m t}_{i j}$ is in general small, we may use the approximation

$$
\operatorname{In}\left(1+\overline{\mathrm{mt}}_{i j}\right)=\overline{\mathrm{mt}}_{i j}-\frac{\left(\overline{\mathrm{m}}_{i j}\right)^{2}}{2}+\ldots
$$

and retain the first term only.

Equation (17) can then be solved by least squares for estimates of $\mathrm{I}_{\mathrm{oi}}$, $\overline{\mathrm{m}}$, and their standard deviations along with the residual standard deviation. The estimates can then be transformed back to the original scale and the transmittances calculated.

\section{Comparison}

A comparison of the results obtained from the three methods on 5 sets of data are shown in Tables II and III. The results are in satisfactory agreement as the transmittances always agree to 6 significant figures, and show as insensitivity of the transmittance values to weighting. Small disagreements for $\bar{m}$ are attributed to the uncertainty in its determination and are of an acceptable magnitude. Since similar results are obtained by the three methods where they are applicable, we plan to use Method B in the future.

\section{Equal and Unequal Time Intervals}

It remained to show that the photomultiplier would respond in the same way if the measurements were made at unequal intervals. Normally the time between readings is $60 \mathrm{sec}$. The intervals denoted by brackets in the sequence above were deliberately changed to $75 \mathrm{sec}$. and the results compared to the results obtained for all of the intervals equal to $60 \mathrm{sec}$. The transmittances $\tau_{1}, \tau_{2}, \tau_{3}$ with the standard errors $\Delta \tau_{1}, \Delta \tau_{2}, \Delta \tau_{3}$ are shown in Table IV for equal and unequal time intervals. The difference shows no systematic difference between equal and unequal time intervals. 


\section{E. Temperature Control}

A pneumatically controlled sliding sample holder was constructed. The temperature of samples mounted in this holder is controlled by water circulated in the holder and in a jacket surrounding the filter to also maintain the temperature of the air surrounding the filter. The holder-jacket combination is three point spring loaded.

The circulating water temperature is provided by a bath which was modified. The heaters and refrigerator (approximately 670 watts each) of the bath were isolated and adjusted so that in combination they yield a nearly constant temperature. Then, a 300 watt heater was installed to "tune" the temperature to the desired level. A special proportional controller was obtained which shuts off the heater or refrigerator (depending on whether one desires a lower or higher temperature) for large temperature changes (several degrees C) until the temperature reaches the range where the 300 watt heater is cycled to maintain a constant temperature as detected by a thermistor placed in the bath.

The actual temperature of the specimen to be measured will be detected by a high quality thermistor through which a calibrated current will be passed by means of a bridge. The calibrated output will be measured by means of a digital voltmeter. Accuracies of $0.1{ }^{\circ} \mathrm{C}$ or better are the design goal with this system, but tests of the complete system have not yet been performed.

\section{Extension of Wavelength Range into the Ultraviolet}

\section{A. New Optics}

Since lenses are chromatic, it was necessary to convert from lenses to mirrors on the source side of the instrument as shown in Figure 1 to extend the wavelength range into the ultraviolet.

Light from the source being used is diverted by a $25 \mathrm{~mm}$ diameter flat mirror into a collimating mirror which is either a $177 \mathrm{~mm}$ focal length off-axis parabola (off-axis by $15^{\circ}$ ), a $290 \mathrm{~mm}$ spherical mirror, or a $390 \mathrm{~mm}$ spherical mirror with $50 \mathrm{~mm}$ diameters. The collimated light travels along the optical bench until it is incident upon a $50 \mathrm{~mm}$ square flat mirror which diverts the light into a $34 \mathrm{~mm}$ diameter off-axis parabola (off-axis by $8.5^{\circ}$ ) of focal length $195 \mathrm{~mm}$ which focuses the light on the entrance slit of the predisperser. The particular collimating mirror used depends on the magnification necessary to fill the predisperser entrance slit with an image of the source being used. No deterioration of the uniformity of the light beam in the sample compartment was observed upon introduction of these mirrors.

A new grating blazed at $200 \mathrm{~nm}$ with 600 grooves/mm was obtained for the wavelength range of $200 \mathrm{~nm}$ to $800 \mathrm{~nm}$. A Twyman-Green Interferometer was used to determine that the grating was flat to 0.3 fringe. The uniformity of the sample compartment beam with the deuterium lamp described below and new grating is shown in Figure 4 for $200 \mathrm{~nm}$ and $400 \mathrm{~nm}$.

The wavelength scale of the 1 meter Czerny-Turner monochromator using the new grating was calibrated for entrance and exit apertures of both $1 / 4 \mathrm{~mm}$ and $1 \mathrm{~mm}$ diameter with predisperser slit widths of $0.5 \mathrm{~mm}$ and $1.5 \mathrm{~mm}$ respectively. It was necessary to use a wider predisperser slit for the $1 \mathrm{~mm}$ monochromator aperture so that the bandpass is determined by the grating rather than the prism predisperser. The results are shown in Figure 5 . The wavelength correction $\Delta \lambda$ equal to the dial reading, $\lambda_{\mathrm{cn}}$, minus the true wavelength, $\lambda_{\text {TRUE }}$, is plotted versus wavelength, $\lambda$. The wavelength scale was calibrated by scanning across atomic line spectra of $\mathrm{Hg}, \mathrm{Zn}, \mathrm{He}, \mathrm{Ne}, \mathrm{Cd}, \mathrm{Cs}$, and $\mathrm{Rb}$. The centroid wavelength was determined for each atomic line scanned. The reason for using the centroid is that for a sufficiently narrow bandpass the transmittance $\tau_{\lambda}$ of a filter at wavelength $\lambda$, is

$$
\tau_{\lambda}=a+b \lambda
$$

where $\mathrm{a}$ and $\mathrm{b}$ are constants. Then, the measured transmittance $\tau_{M}$ will be

$$
\tau_{M}=\frac{\int s_{\lambda} \tau_{\lambda} d \lambda}{\int s_{\lambda} d_{\lambda}}=a+b \bar{\lambda}
$$


where $\bar{\lambda}$, the centroid is

$$
\bar{\lambda}=\frac{\int s_{\lambda} \lambda d \lambda}{\int s_{\lambda} d \lambda}
$$

The centroid is measured by scanning the wavelength dial to obtain the signals, $s_{\lambda}$, resulting from the atomic line. It should be noted that the atomic lines chosen for the large aperture (1 mm diameter) had to be chosen carefully so that neighboring lines did not shift the centroid. The uncertainty in the wavelength setting is estimated to be a $0.020 \mathrm{~nm}$ random error superimposed on a $0.015 \mathrm{~nm}$ systematic setting error using $\lambda_{\mathrm{cn}}=\bar{\lambda}$.

\section{B. Sources}

\section{Tungsten-Quartz-Bromide Lamp}

It is possible to make measurements with this instrument down to approximately $350 \mathrm{~nm}$ with a tungsten-quartz-bromide lamp which exhibits the moire effect and approximates a uniform source. For shorter wavelengths, it was necessary to use a deuterium lamp [7].

\section{Deuterium Lamp}

A deuterium lamp with a 4.0 by $1.5 \mathrm{~mm}$ rectangular aperture was used in the wavelength range of 200 to $400 \mathrm{~nm}$. The drift of the lamp-detection system combination was approximately linear over a 30 minute time interval. A typical drift curve is shown in Figure 6 with the ordinate showing the results of the output of the current to frequency converter for a ten second integration time and the abscissa denotes time in minutes.

The measured relationship between the noise $d I$ and anode current $I$ is shown in Figure 7 where dI/I is plotted vs. I for a photomultiplier voltage of $850 \mathrm{~V}$. The ratio dI/I is approximately

$$
\frac{\mathrm{dI}}{\mathrm{I}}= \begin{cases}(22 / \mathrm{I})^{\frac{1}{2}} \times 10^{-8} & \mathrm{I}<10^{-7} \text { amperes } \\ 1.5 \times 10^{-4} & \mathrm{I}>10^{-7} \text { amperes }\end{cases}
$$

This shows a similarity to curves published for the tungsten strip lamp used in the visible wavelength range $[1,2]$.

\section{Fluorocarbon Coated Sphere with Efficient Design}

A highly effective averaging sphere for ultraviolet, visible, and near infrared wavelengths has been developed. A detailed description is given in Ref. [8]. A schematic of this sphere using a fluorocarbon coating and a symmetrical design is shown in Figure 8 . The sphere has a $92 \mathrm{~mm}$ diameter with entrance port of $28 \mathrm{~mm}$ and exit port of $44 \mathrm{~mm}$ diameters. In order to trap the specular component of the first reflection by the sphere wall and to complete the symmetry of the sphere, a black cavity is placed opposite the entrance port. The opening to which the cavity is placed is the same size as entrance port.

The fluorocarbon coating was approximately $5 \mathrm{~mm}$ thick. Even though the photomultiplier views the first reflection of the sphere wall, the averaging effectiveness is adequate for high accuracy work as shown in Section III-C below. Its measured efficiency is listed here for several wavelengths. These efficiency values may include a contribution due to a slight fluorescence. Although this fluorescence will not cause a problem in most spectrophotometric applications, proper precautions should be taken when this coating is used in applications in which fluorescence of the sphere wall could cause an error. 


\section{Linearity in the UItraviolet}

The linearity of the electronics and photomultiplier in the ultraviolet was measured using the double aperture method [6] in the same manner as in the visible. The linearity correction $\Delta \tau$ is shown below as a function of transmittance $\tau$ along with the standard deviation of the linearity correction $\delta(\Delta \tau)$ at $280 \mathrm{~nm}$ for a full scale anode current of $3 \times 10^{-7}$ amperes.

\begin{tabular}{|c|c|c|}
\hline$\tau$ & $\begin{array}{c}\Delta \tau \\
\left(\times 10^{-4}\right)\end{array}$ & $\begin{array}{r}\delta(\Delta \tau) \\
\left(\times 10^{-5}\right)\end{array}$ \\
\hline .1 & 1.33 & .93 \\
\hline .2 & 2.35 & 1.40 \\
\hline .3 & 3.06 & 1.67 \\
\hline .4 & 3.48 & 1.99 \\
\hline .5 & 3.60 & 2.40 \\
\hline .6 & 3.43 & 2.78 \\
\hline .7 & 2.98 & 2.93 \\
\hline .8 & 2.26 & 2.64 \\
\hline .9 & 1.26 & 1.73 \\
\hline 1.0 & 0 & 0 \\
\hline
\end{tabular}

\section{E. Polarization}

The light in the spectrophotometer is partially polarized. The polarization ratio is shown in Figure 9 for the wavelength range 200 to $400 \mathrm{~nm}$. The polarization ratio is expressed as $\mathrm{T}_{90^{\circ}} / \mathrm{T}_{0^{\circ}}$ where $\mathrm{T}_{90^{\circ}}$ and $\mathrm{T}_{0}$ are the transmittances of an ultraviolet polarizer with the electric vector parallel and perpendicular to the grating grooves.

Since the air-spaced Glan-Thompson prisms mentioned in Section I above do not transmit wavelengths down to $200 \mathrm{~nm}$, a well defined state of polarization was obtained at shorter wavelengths below the cut-off of the prisms with a pair of UV polarizers.

\section{F. Stray Radiant Energy}

Stray radiant energy in the ultraviolet was measured following ASTM method E 387 [9] using sharp cutoff solutions. The "apparent" transmittance of the solution below the cutoff indicates the stray radiant energy. Since the "apparent" transmittance was less than the standard error based on 17 measurements, all that can be stated is that the stray light is less than the noise. The wavelengths at which the measurements were made and the solution used with the upper bound for stray radiant energy are listed below:

Wavelength

$342.5 \mathrm{~nm}$

235

209
Solution

$1 \mathrm{~cm} 50 \mathrm{~g} / 1$ iter $\mathrm{NaNO}_{2}$ aqueous

$1 \mathrm{~cm}$ acetone

$1 \mathrm{~cm} 10 \mathrm{~g} / \mathrm{liter} \mathrm{NaI}$ aqueous

$1 \mathrm{~cm} 10 \mathrm{~g} / 1$ iter $\mathrm{NaBr}$ aqueous

\section{Stray Radiant Energy}

$$
\begin{aligned}
& <1.4 \times 10^{-6} \\
& <1.6 \times 10^{-5} \\
& <2.7 \times 10^{-6} \\
& <1.5 \times 10^{-5}
\end{aligned}
$$

Also, as a check, $2 \mathrm{~cm}$ of each solution was measured without any significant decrease in "transmittance" showing that we were indeed measuring stray radiant energy.

Since it was desired to use the new grating (200 nm blaze-600 grooves $/ \mathrm{mm}$ ) in the visible spectral range and since it is necessary to use a wider predisperser entrance slit, the stray radiant energy was measured in the visible spectral range using methylene blue aqueous solution recommended in ASTM Method E 387 [9] with a one cm solution and two $1 \mathrm{~cm}$ solutions in series. The stray radiant energy measured at $660 \mathrm{~nm}$ for the $1 \mathrm{~cm}$ solution was found to be $5 \times 10^{-6}$ and for the $2 \mathrm{~cm}$ solution was found to be $2 \times 10^{-6}$. This compares with measurements made with two cobalt blue filters in series (Corning 5551, approximately $3 \mathrm{~mm}$ thick) which indicated a stray radiant energy of $1.6 \times 10^{-6}$ at $640 \mathrm{~nm}$. 
Measurements indicating stray radiant energy were also made by measuring the apparent transmittance of a selenium red filter and two filters in series at wavelengths below their "cutoff" with the following results.

\begin{tabular}{cc}
$\begin{array}{c}\text { Wavelength } \\
\text { (nm) }\end{array}$ & $\begin{array}{c}\text { Stray Radiant Energy } \\
\text { (One Filter) }\end{array}$ \\
\hline 400 & $1.9 \times 10^{-6}$ \\
450 & $3.8 \times 10^{-6}$ \\
500 & $1.5 \times 10^{-5}$
\end{tabular}

$\begin{aligned} & \text { Stray Radiant Energy } \\ & \text { (Two Filters) }\end{aligned}$
$\begin{aligned} & 7.5 \times 10^{-7} \\ & 2.3 \times 10^{-6} \\ & 8.8 \times 10^{-6}\end{aligned}$

\section{G. Actual Measurements}

Two high quality fused quartz specimens, 6.3 and $12.7 \mathrm{~mm}$ thick, were measured at $280.1 \mathrm{~nm}$. After cleaning with isopropyl alcohol followed by distilled water, a history of their transmittance was observed for several weeks during which no significant change was observed. The transmittance, $\tau$, is listed in Table $V$ along with the standard error based on four measurements, $\Delta \tau$. The $12.7 \mathrm{~mm}$ sample was then cleaned and remeasured with a significant change in transmittance. It is concluded that sample handling is very important in the ultraviolet as it is in the visible spectrum.

\section{Effectiveness of Light Averaring Devices}

When a $1 \mathrm{~cm}$ thick sample having an index of refraction of 1.5 is placed in a collimated beam of light at an angle of $4^{\circ}$ to the normal, the beam is deflected approximately $0.2 \mathrm{~mm}$. This type of deflection can cause an error in a transmittance measurement since photomultiplier cathodes are non-uniform. Our end-on photomultiplier was scanned across the beam to see what effect a deflection of the beam would cause, both with and without different averaging devices preceding the cathode. Also, the efficiencies of some averaging devices were measured by observing the signal with the averaging device and then integrating over selected areas of the bare photomultiplier. More data on efficiencies are presented in Refs. [4], [8], and [10]. Unless otherwise specified, all measurements were made at $525 \mathrm{~nm}$. The effectiveness of the averagers was tested by scanning the averager-detector combination in a square array of \pm 1 or $\pm 1.5 \mathrm{~mm}$ in the plane perpendicular to the light beam in the $x, y$ directions and at $45^{\circ}$ to the $x-y$ axes. This was done in 5 steps of 0.2 or $0.3 \mathrm{~mm}$ in eight directions. These measurements were made feasible by the MIDAS system mentioned earlier. Two translation stages powered by stepping motors were controlled by MIDAS coupled to a minicomputer which turned the motors a preselected number of steps (1 step corresponded to a displacement of $0.0127 \mathrm{~mm}$ ). The six points in a scan (center position and 5 intervals) were measured by moving back and forth in a symmetrical fashion four times. The resultant data for each spatial point were fitted to straight lines as a function of time in a manner such that the drift of the system was eliminated. A detector displacement in the upward direction looking at the detector was arbitrarily called north $(\mathrm{N})$ and to the right was called east $(E)$. The ordinate in the curves is the ratio of the signal corrected for the zero signal at the designated position divided by the signal at the center position I(O) corrected for the zero signal.

To insure that moving the detector in the earth's magnetic field was not responsible for the observed effects, an extra magnetic shield was put around the detector housing in addition to the regular mu-metal shield around the photomultiplier tube. Further, a magnetically shielded tritium activated phosphor source was attached to the sphere-detector combination and the three scanned together. The results shown in Figure 10 verify that the ambient earth magnetic field was not causing the effects described below. The curves shown in Figure 10 are a least square linear fit to the experimental data normalized to unity at the center position with the brackets denoting \pm 2 standard deviations of the fitted curve.

\section{A. Bare Photomultiplier Cathode}

The photomultiplier tube in the reference instrument was scanned as described above with a $10 \mathrm{~mm}$ diameter collimated light beam incident upon it with wavelength equal to $525 \mathrm{~nm}$. The deviations from the center position $\mathrm{I} / \mathrm{I}(0)$ are shown in Figure 11 . One sees 
that for our photomultiplier tube without an averager, errors of the order of $5 \%$ can be expected for a $1 \mathrm{~mm}$ beam displacement - a rather serious amount. The standard errors on this scale are negligible.

\section{B. Intermediate Sphere Used for Visible Spectrum}

The sphere shown in Figure 3 has an efficiency of approximately $8.5 \%$. It has a diameter of $76 \mathrm{~mm}$ with entrance and exit ports of $30 \mathrm{~mm}$ and $44 \mathrm{~mm}$ respectively. It was coated with a $3 \mathrm{~mm}$ thick layer of high purity pressed $\mathrm{BaSO}_{4}$. The efficiency of this type of sphere can be increased greatly by the use of a collar [4]. To test how effectively this sphere averages, a $10 \mathrm{~mm}$ diameter collimated beam was used. The results of a scan performed as described above yielded the results shown in Figure 12. It is seen that a displacement of the light beam by $1 \mathrm{~mm}$ (a displacement over 5 times larger than that expected from a routine transmittance measurement) gives an error of $\pm 10^{-4}$ transmittance units so that in practice an error at most of several parts in the fifth decimal place may be expected at $525 \mathrm{~nm}$. The curves shown in Figure 12 are a least squares linear fit to the experimental data normalized to unity at the center position with the brackets denoting \pm 2 standard deviations of the fitted curve. The possibility of a correction for beam displacements exists. Also, for large beam displacements $(\approx 1 \mathrm{~mm})$, a small effect is observed and alignment is not sritical. Furthermore, simplicity of design may be considered an advantage for this type of sphere. Scans performed with linearly polarized light with the electric vector vertical and horizontal yielded identical results within the uncertainty of the measurements so that the polarization of the incident beam is not important.

\section{Fluorocarbon Coated Sphere with Efficient Design}

The sphere described briefly above in Section II-C and in detail in Ref. [8] was tested for its-averaging effectiveness as described above at wavelengths $250 \mathrm{~nm}$ and $525 \mathrm{~nm}$. Results for averaging effectiveness comparable with those for the sphere described in Section III-B were obtained. These results using a $10 \mathrm{~mm}$ diameter collimated beam are shown in Figure 13 for wavelength of $250 \mathrm{~nm}$ and Figure 14 for wavelength of $525 \mathrm{~nm}$. The smooth curves are a least squares linear fit to the experimental points normalized to unity at the center position with the brackets denoting \pm 2 standard deviations of the fitted curve.

\section{Sphere with $\mathrm{BaSO}_{4}$ Target}

This type of sphere is described more fully elsewhere [10]. The sphere used has a $25 \mathrm{~mm}$ diameter $\mathrm{BaSO}_{4}$ target mounted near the center of the $150 \mathrm{~mm}$ diameter sphere with a $10 \mathrm{~mm}$ diameter entrance aperture and $50 \mathrm{~mm}$ diameter exit port. This sphere was lined with 6 coats of sprayed $\mathrm{BaSO}_{4}$ having a total thickness of approximately $1 \mathrm{~mm}$. It was scanned with a $5 \mathrm{~mm}$ diameter collimated beam incident upon it. The results are shown in Figure 15 for wavelength of $525 \mathrm{~nm}$. The curves in this figure are a least squares quadratic fit to the experimental data normalized to unity at the center position with the brackets denoting \pm 2 standard deviation of the fitted curve. For a $1 \mathrm{~mm}$ beam displacement, errors of the order of several parts in $10^{-4}$ may be expected. This sphere was also tested using a focused beam $1 \mathrm{~mm}$ in diameter at the entrance port with a $3.5 \mathrm{~mm}$ diameter illuminated area on the target with similar results as for the collimated beam.

\section{E. Sphere with Fluorescent Target}

Another new type of efficient averaging sphere was developed by Mielenz, Mavrodineanu and Cehelnik [10] for use with ultraviolet and visible wavelengths. This $\mathrm{BaSO}_{4}$ coated sphere utilizes a fluorescent solution as a target which converts ultraviolet wavelengths into visible wavelengths. A $102 \mathrm{~mm}$ diameter sphere with $40 \mathrm{~mm}$ diameter target and with 10 $\mathrm{mm}$ diameter entrance port and $50 \mathrm{~mm}$ diameter exit port of this design was tested at wavelengths $250 \mathrm{~nm}$ and $525 \mathrm{~nm}$ with incident collimated beam of $5 \mathrm{~mm}$ diameter. The results are shown in Figure 16 for the wavelength $250 \mathrm{~nm}$ and Figure 17 for wavelength $525 \mathrm{~nm}$. The smooth curves are a least squares linear or quadratic fit, respectively, to the experimental points normalized to unity at the center position with the brackets denoting \pm 2 standard deviations of the fitted curve. 


\section{F. UV Averager with Ground Quartz Diffusers}

An averager consisting of two diffusing glasses at either end of a white diffusing tube has been described by Budde [11]. A similar device was constructed using two $6 \mathrm{~mm}$ thick Suprasil 2 discs which are $60 \mathrm{~mm}$ in diameter and ground on both sides with 80 mesh grit. They were placed at either end of a $50 \mathrm{~mm}$ long-60 mm diameter white diffusing tube with one disc $10 \mathrm{~mm}$ from the cathode and the other $60 \mathrm{~mm}$. This arrangement has an efficiency of approximately $20 \%$ at $525 \mathrm{~nm}$. The results from the averaging test are shown in Figure 18. One can expect errors of several parts in $10^{-3}$ for a $1 \mathrm{~mm}$ beam displacement more than an order of magnitude greater than for the spheres tested. No significant differences in efficiency or averaging properties were observed upon replacing the white diffusing tube with an aluminized tube.

\section{G. Etched GI ass}

A single piece of glass coarse ground and then acid polished on one side with HF acid was placed $560 \mathrm{~mm}$ from the photomultiplier cathode and scanned. It was hoped that this glass which approximates an array of small lenses, would improve the averaging. However, curves similar to those obtained for the device described in Section III-F resulted, and the errors were factor of 2 greater.

\section{H. Summary}

Since the response of the detector used for these tests was non-uniform with spot displacement, the results show that all of the spheres used are good averagers. The error caused by displacing the light beam are probably due to non-uniform sphere coatings and sphere geometry. The small differences between different types of spheres may also be caused by these same two factors as well as other parameters such as spot size. No attempt was made to investigate the cause of the differences. The other type diffusers tested here can probably be used in many applications where high accuracy is not required even though the particular devices tested here did not average as well as the spheres. 


\section{Light Collection Solid Anzle for Intermediate Sphere}

We have made calculations of the solid angle for three possible sample-to-sphere distances and for three positions on the samples. Two positions on the sample represent extreme values and the third position was on the optical axis.

The opening in the sphere is formed by the intersection of a cylinder and the sphere in $x-y-z-$ space. The equation for a cylinder in coordinates on its axis is

$$
x^{2}+y^{2}=a^{2}
$$

where $\mathrm{a}$ is the radius of the cylinder as shown in Figure 19a. We can transfer the origin to the center of the sphere (on the $y-z$ plane) by the equation

$$
y^{\prime}=y-b
$$

where $b$ is the distance between the center of the sphere and the cylinder axis. Then,

$$
x^{\prime 2}+\left(y^{\prime}+b\right)^{2}=a^{2} \text {. }
$$

As shown in Figure $19 a$, we can rotate the $z^{\prime}$ axis to the intersection of the sphere and the cylinder axis by an angle $\theta$,

$$
\theta=\arcsin (b / R)+\pi
$$

Then

$$
y^{\prime}=y^{\prime \prime} \cos \theta+z^{\prime \prime} \sin \theta
$$

and

$$
x^{\prime \prime 2}+\left(y^{\prime \prime} \cos \theta+z^{\prime \prime} \sin \theta+b\right)^{2}=a^{2} .
$$

Transforming to spherical coordinates as shown in Figure 19b

$$
\begin{aligned}
x^{\prime \prime} & =r \cos \alpha \\
y^{\prime \prime} & =r \sin \alpha \cos \phi \\
z^{\prime \prime} & =r \sin \alpha \sin \phi
\end{aligned}
$$

where $\alpha=$ elevation and $\phi=$ azimuth, we have,

$$
a^{2}=r^{2} \sin ^{2} \alpha \sin ^{2} \phi+(r \sin \alpha \cos \phi \cos \theta+r \cos \alpha \sin \theta+b)^{2} .
$$

When $r=R=$ radius of the sphere, we have all the points on the intersection of the cylinder and sphere,

$$
a^{2}=R^{2} \sin ^{2} \alpha \sin ^{2} \phi+(R \sin \alpha \cos \phi \cos \theta+R \cos \alpha \sin \theta+b)^{2} .
$$

As seen in Figure 20a the distance between a point on the sample and the center of the sphere is

$$
\overline{\mathrm{A}}^{2}=(\mathrm{b}-\mathrm{y})^{2}+\overline{\mathrm{A}_{0} \mathrm{D}^{2}}
$$

Also,

$$
\angle A O B=\angle A O D-\angle B O D=\arctan \left(\frac{\overline{A_{0} D}}{b-y}\right)-\arccos (b / R) .
$$


From Figure $20 \mathrm{a}$ and $20 \mathrm{~b}$, using spherical trigonometry, we see that

$$
\alpha^{\prime}=\operatorname{Arccos}\{\cos \alpha \cos A O B+\sin \alpha \sin A O B \cos \phi\} .
$$

so that the distance between a point on a sample and the points which satisfy Eq. (A-11) is

$$
\mathrm{d}^{2}=\mathrm{R}^{2}+\overline{\mathrm{AO}}^{2}-2 \mathrm{R} \overline{\mathrm{AO}} \cos \alpha^{\prime} .
$$

The angle between $\mathrm{OC}$ and $\mathrm{AC}$ is $\gamma=\alpha^{\prime}+\beta^{\prime}$ where

$$
\beta^{\prime}=\arcsin \left(\frac{R \sin \alpha^{\prime}}{d}\right)
$$

by the law of sines. An elemental area-is then

$$
\mathrm{dA}=\mathrm{R}^{2} \sin \alpha \mathrm{d} \alpha \mathrm{d} \phi
$$

and an elemental solid angle is

$$
\mathrm{d} \Omega=\left(\mathrm{dA} / \mathrm{d}^{2}\right) \cos \gamma
$$

Numerical integration using a computer to solve Eq. (A-17) was done for $\alpha=0.5^{\circ}, 1.5^{\circ}$, $2.5^{\circ}$, and $\phi=0^{\circ}$ to $360^{\circ}$ in steps of $1^{\circ}$ and $\mathrm{d} \alpha=\mathrm{d} \phi=1^{\circ}$ for all values of $\alpha$ and $\phi$ bounded by Eq. $(A-11)$.

In our case,

$$
\begin{aligned}
& \mathrm{R}=76.2 \mathrm{~mm} \\
& \mathrm{a}=15.0 \mathrm{~mm} \\
& \mathrm{~b}=44.45 \mathrm{~mm}
\end{aligned}
$$

and

$$
\overline{\mathrm{A}_{0} \mathrm{~B}}=330,550 \text {, and } 750 \mathrm{~mm} \text {. }
$$

Also, a calculation was made for a $1^{\circ}$ tilt of the sphere or a positioning accuracy of $1.3 \mathrm{~mm}$. The results are shown in Table VI.

We see that a tilt error at $330 \mathrm{~mm}$ causes a $1.84 \%$ error in the solid angle which is .0067 steradian. Since a hemisphere contains $2 \pi$ steradians, approximately $.1 \%$ of the scattered light is collected. Hence, even if the ratio of specular transmittance to scattered transmittance is 1 , the error introduced will be approximately 0.000018 for a $10 \%$ transmitting filter.

We also see that for our beam sizes up to $20 \mathrm{~mm}$ by $20 \mathrm{~mm}$ the variation with position on the sample gives a maximum error at $330 \mathrm{~mm}$ of $2.11 \%$. Hence, this error is approximately the same as for misalignment. However, the actual error will be much smaller since the variation of solid angle with position is approximately linear, and solid angles on opposite sides of the optic axis tend to compensate.

\section{$* * * * * * * * * * * *$}

\section{ACKNOWLEDGMENTS}

Many of the ideas implemented in this report were due to Dr. W. H. Venable, Jr. I also wish to thank him for the many day-to-day discussions which lead to progress in the work. Dr. K. D. Mielenz made some suggestions and provided several of the averaging spheres tested here. Mr. Victor Weidner assisted with the design of several components described and with some of the measurements. Dr. J. J. Hsia helped with the theoretical background necessary to support the experimental work. 
[1] Mielenz, K. D., Eckerle, K. L., Madden, R. P., Reader, J., "New Reference Spectrophotometer", App1. Opt. 12, 1630 (1973).

[2] Mielenz, K. D., Eckerle, K. L., "Design, Construction, and Testing of a New High Accuracy Spectrophotometer", Nat. Bur. Stand. (U.S.) Tech. Note 729, 60 pages (1972).

[3] Venable, W. H. and Hsia, J. J., "Describing Spectrophotometric Measurements", Nat. Bur. Stand. (U.S.) Tech. Note 594-9, 50 pages (1974).

[4] Mielenz, K. D., Eckerle, K. L., "Averaging Spheres Without Target", App1. Opt. 14, 1649 (1975).

[5] Popenoe, C. H., Campbe11, M. S., "MIDAS, Modular Interactive Data Acquisition System Description and Specification", Nat. Bur. Stand. (U.S.) Tech. Note 790, 49 pages (1973).

[6] Mielenz, K. D., Eckerle, K. L., "Spectrophotometer Linearity Testing Using the Double Aperture Method", App1. Opt. 11, 2294 (1972).

[7] Mielenz, K. D., Mavrodineanu, R., Cehelnik, E. D., "Adaptation of a High Accuracy Spectrophotometer for U1traviolet Work", J. Res. Nat. Bur. Stand. (U.S.), 78A (Physics and Chemistry), No. 5, 631 (September, October 1974).

[8] Eckerle, K. L., Venable, W. H. Jr., and Weidner, V. R., "A Highly Effective Averaging Sphere for Ultraviolet, Visible, and Near Infrared Wavelengths", App1. Opt. 15, 703 (1976)

[9] "Estimating Stray Radiant Energy", 1970 Annual Book of ASTM Standards, Part 30, (1970), p. 1154 .

[10] Mielenz, K. D., Mavrodineanu, R., and Cehelnik, E. D., "Efficient Averaging Spheres for Visible and U1traviolet Wavelengths", App1. Opt. 14, 1940 (1975).

[11] Budde, W., Proc. Fourth IMEKO Symposium, Prague 1969, p. 167. 


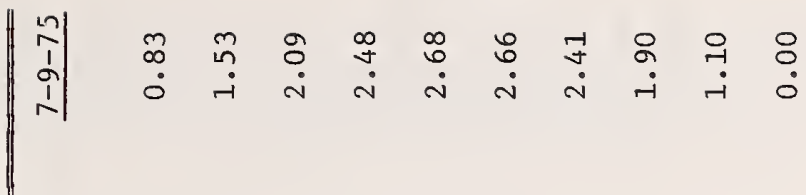

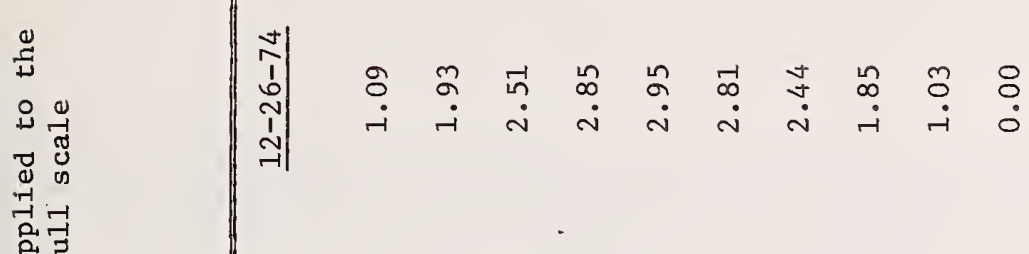

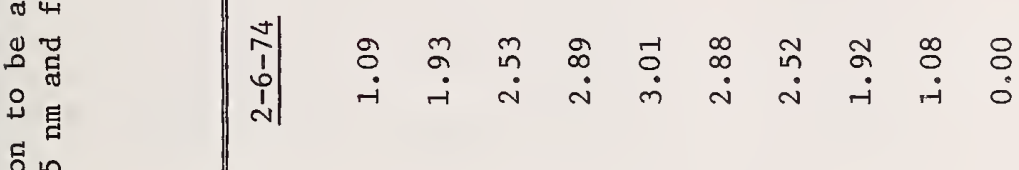

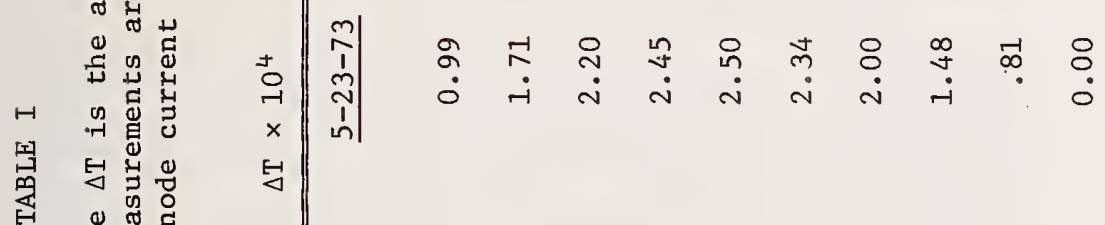

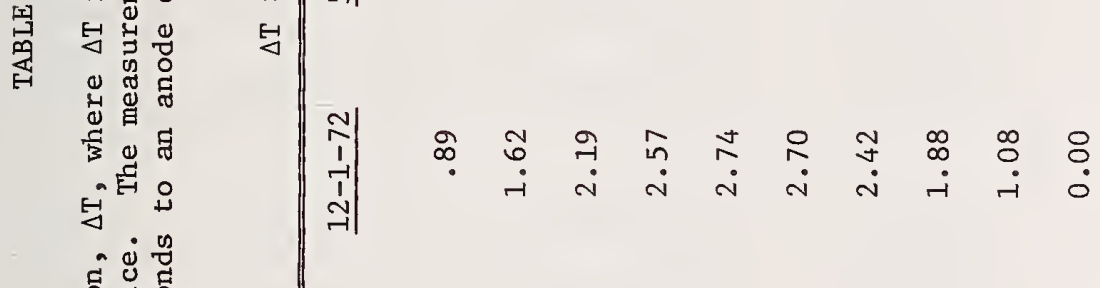

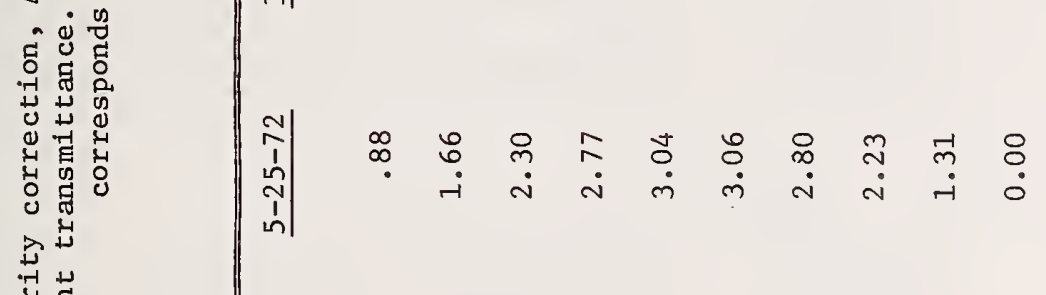

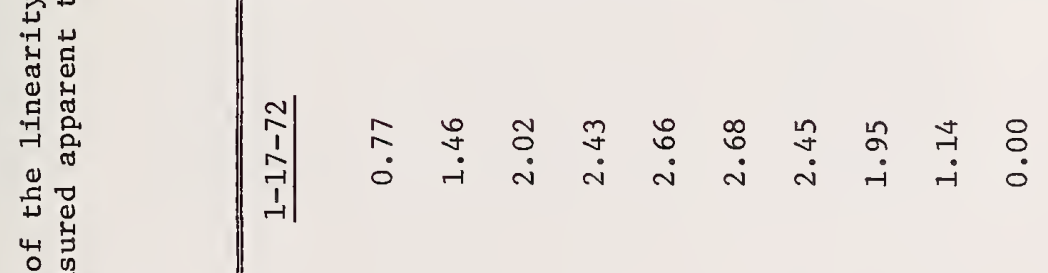

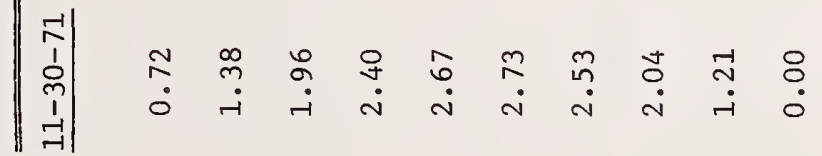

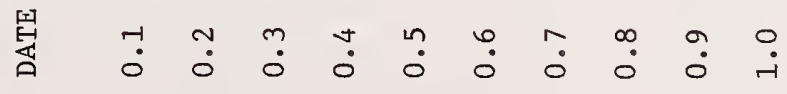


The set of $I_{o i}$ and $\bar{m}$ obtained from three methods of calculation as described in Section I-D of the text

for five sets of data.

R U N 1

\begin{tabular}{|c|c|c|c|c|c|}
\hline METHOD & $I_{01} \times 10^{-5}$ & $\mathrm{I}_{02} \times 10^{-5}$ & $\mathrm{I}_{03} \times 10^{-5}$ & $\mathrm{I}_{04} \times 10^{-5}$ & $\overline{\mathrm{m}} \times 10^{5}$ \\
\hline A & 0.467276 & 0.160195 & 0.0925475 & 0.0523475 & 0.4010 \\
\hline B & 0.467276 & 0.160195 & 0.0925475 & 0.0523475 & 0.4459 \\
\hline \multirow[t]{2}{*}{ C } & 0.467282 & 0.160196 & 0.0925482 & 0.0523466 & 0.4020 \\
\hline & & $R \cup N$ & 2 & & \\
\hline A & 0.464257 & 0.159155 & 0.0919774 & 0.0520024 & -0.1253 \\
\hline B & 0.464258 & 0.159155 & 0.0919774 & 0.0520024 & -0.1338 \\
\hline \multirow[t]{2}{*}{ C } & 0.464258 & 0.159157 & 0.0919747 & 0.0520036 & -0.1239 \\
\hline & & $R \cup N$ & 3 & & \\
\hline A & 0.462987 & 0.158728 & 0.0916842 & 0.0518415 & -0.1214 \\
\hline B & 0.462987 & 0.158728 & 0.0916844 & 0.0518418 & -0.0865 \\
\hline \multirow[t]{2}{*}{$\mathrm{C}$} & 0.462985 & 0.158726 & 0.0916864 & 0.0518402 & -0.1212 \\
\hline & & $R \cup N$ & 4 & & \\
\hline A & 0.461984 & 0.158340 & 0.0914620 & 0.0517169 & -0.0761 \\
\hline B & 0.461984 & 0.158340 & 0.0914620 & 0.0517169 & -0.0804 \\
\hline \multirow[t]{2}{*}{$\mathrm{C}$} & - & - & - & - & - \\
\hline & & $R \cup N$ & 5 & & \\
\hline A & 0.465664 & 0.159588 & 0.0922051 & 0.0521601 & 0.0095 \\
\hline B & 0.465665 & 0.159588 & 0.0922052 & 0.0521603 & 0.0369 \\
\hline $\mathrm{C}$ & 0.465663 & 0.159589 & 0.0922063 & 0.0521588 & 0.0106 \\
\hline
\end{tabular}


Transmittances $\left(\mathrm{T}_{1}, \mathrm{~T}_{2}\right.$, and $\left.\mathrm{T}_{3}\right)$ of three filters and estimates of the respective standard errors $\left(S_{1}, S_{2}\right.$, and $\left.S_{3}\right)$ obtained from three methods of calculation as described in Section I-D of the text for five sets of data.

$$
R \cup N \quad 1
$$

\begin{tabular}{ccccccc} 
METHOD & $\mathrm{T}_{1}$ & $\mathrm{~S}_{1}$ & $\mathrm{~T}_{2}$ & $\mathrm{~S}_{2}$ & $\mathrm{~T}_{3}$ & $\mathrm{~S}_{3}$ \\
\hline \hline $\mathrm{A}$ & 0.342827 & 0.0001020 & 0.198057 & 0.0000638 & 0.112027 & 0.0000188 \\
$\mathrm{~B}$ & 0.342827 & 0.0000995 & 0.198057 & 0.0000738 & 0.112027 & 0.0000178 \\
$\mathrm{C}$ & 0.342825 & 0.0000818 & 0.198056 & 0.0000473 & 0.112024 & 0.0000267 \\
& & & $\mathrm{R} \mathrm{U} \mathrm{N}$ & 2 & & \\
$\mathrm{~A}$ & 0.342816 & 0.0000434 & 0.198117 & 0.0000550 & 0.112012 & 0.0000194 \\
$\mathrm{~B}$ & 0.342816 & 0.0000418 & 0.198117 & 0.0000566 & 0.112012 & 0.0000186 \\
$\mathrm{C}$ & 0.342820 & 0.0000636 & 0.198111 & 0.0000368 & 0.112014 & 0.0000208
\end{tabular}

$R \cup N \quad 3$

$\begin{array}{lllllll}\text { A } & 0.342834 & 0.0000631 & 0.198028 & 0.0000453 & 0.111972 & 0.0000149 \\ \text { B } & 0.342833 & 0.0000599 & 0.198028 & 0.0000528 & 0.111972 & 0.0000174 \\ \text { C } & 0.342831- & 0.0000591 & 0.198033 & 0.0000342 & 0.111969 & 0.0000193\end{array}$

R UN 4
A
0.342739
0.0000365
0.197977
0.0000488
0.111945
0.0000225
B
0.342739
0.0000362
0.197977
0.0000490
0.111945
0.0000225
C
$R \cup N$
5
A
0.342709
0.0000505
0.198008
0.0000490
0.112012
0.0000415
B
0.342709
0.0000331
0.198008
0.0000482
0.112013
0.0000457
C
0.342713
0.0000816
0.198011
0.0000471
0.112010
0.0000267 


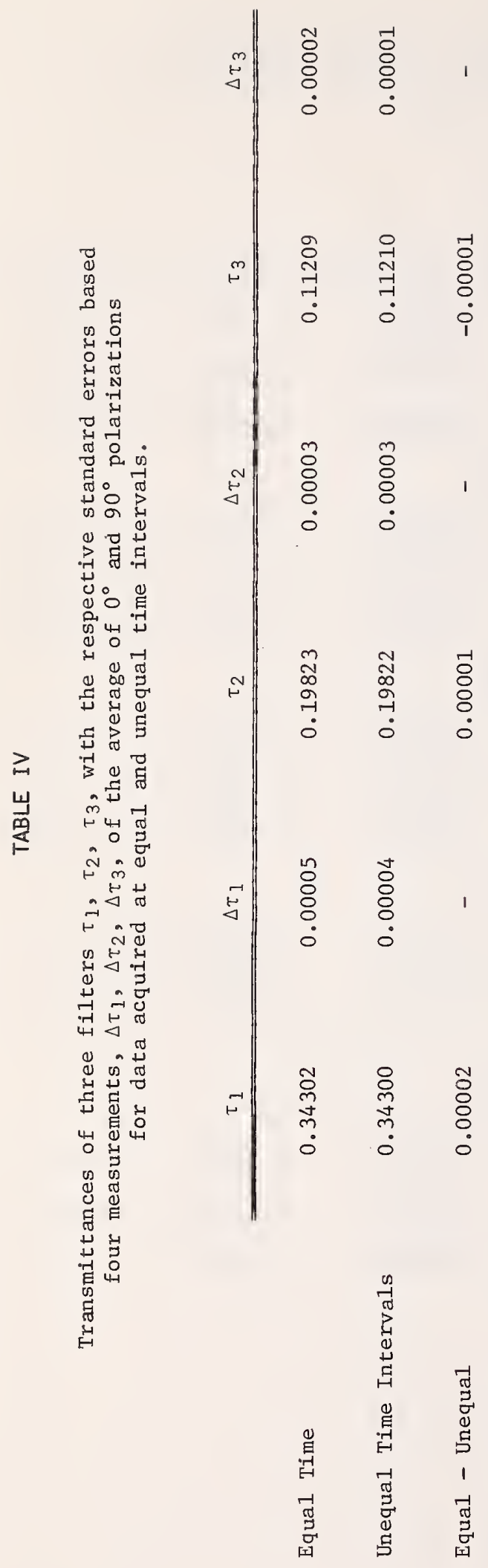


U1traviolet measurements on high quality fused quartz at wavelength of $280.1 \mathrm{~nm}$. Transmittances, $\tau$, are average of $0^{\circ}$ and $90^{\circ}$ polarizations with standard errors based on four measurements, $\Delta \tau$.

\section{$6.3 \mathrm{~mm}$ thick specimen}

D A $T E$

February 13

February 27

March 4

March 5

March 6 $\tau$

$\Delta \tau$
0.91589

0.00014

0.91598

0.00017

0.91583

0.00014

0.91587

0.00012
$12.7 \mathrm{~mm}$ thick specimen

$\tau$ $\Delta \tau$
0.91612
0.00014
0.91502
0.00017

0.91493

0.00015

0.91490

0.00016

0.91616

0.00012

After Cleaning

0.91604

0.00016

After Cleaning

TABLE VI

Results of Calculations for Solid Angle of Acceptance for Intermediate Spheres.

Perfect Alignment

$1^{\circ} \mathrm{Tilt}$

$\begin{array}{cr}\mathrm{d} & \mathrm{y} \\ (\mathrm{mm}) & (\mathrm{mm}) \\ 330 & 0 \\ & -10 \\ & +10 \\ & \\ 550 & 0 \\ & -10 \\ & +10 \\ 750 & 0 \\ & -10 \\ & +10\end{array}$

$\mathrm{y}$
$(\mathrm{mm})$

0

$-10$

$+10$

$-10$

$+10$

$-10$

$+10$

$\Omega$
$($ Steradians $)$
.006687
.006810
.006546
.002406
.002434
.002376
.001294
.001305
.001282

$\Omega$
$($ Steradians)
.006564
.006691
.006418
.002368
.002397
.002336
.001274
.001286
.001262




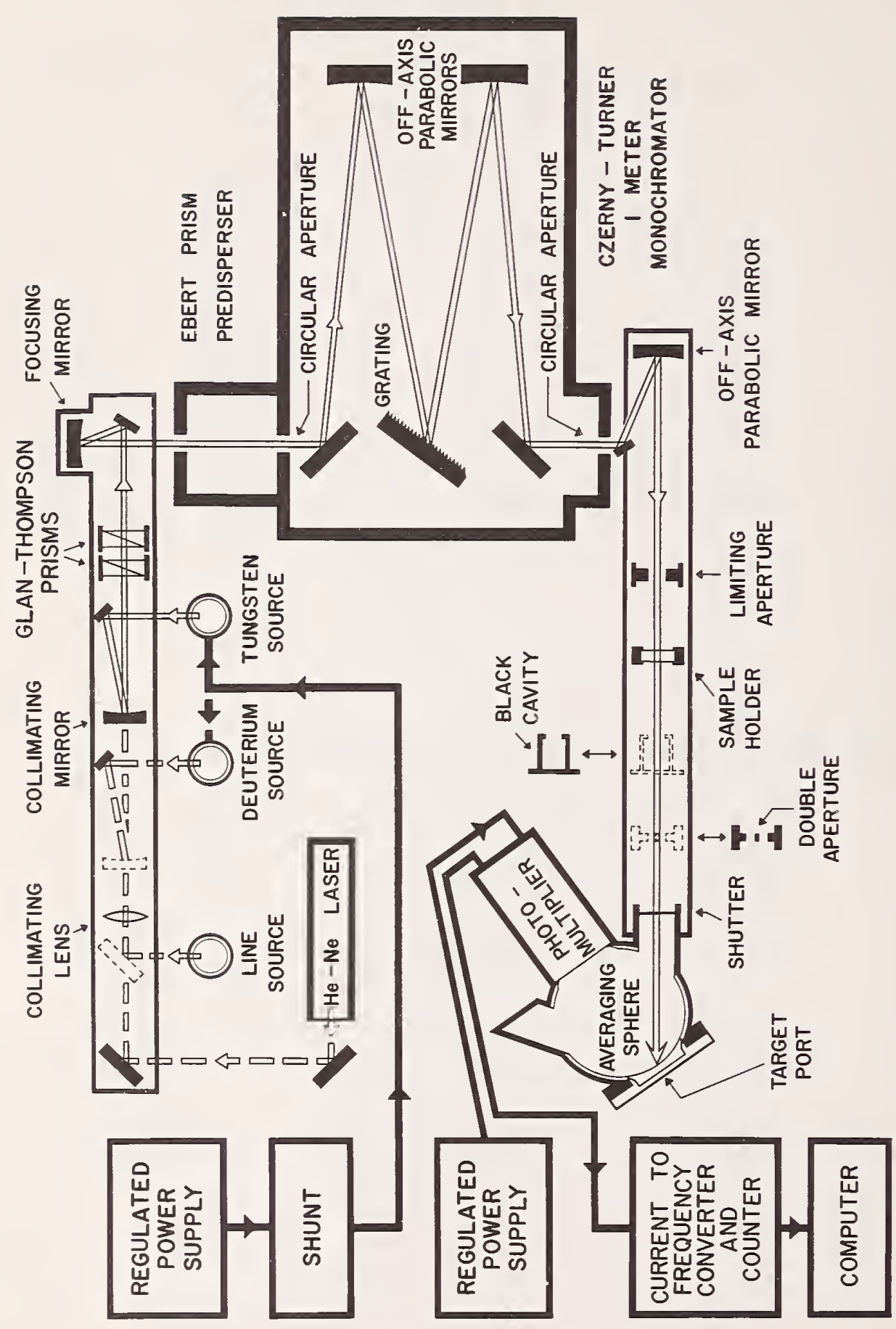




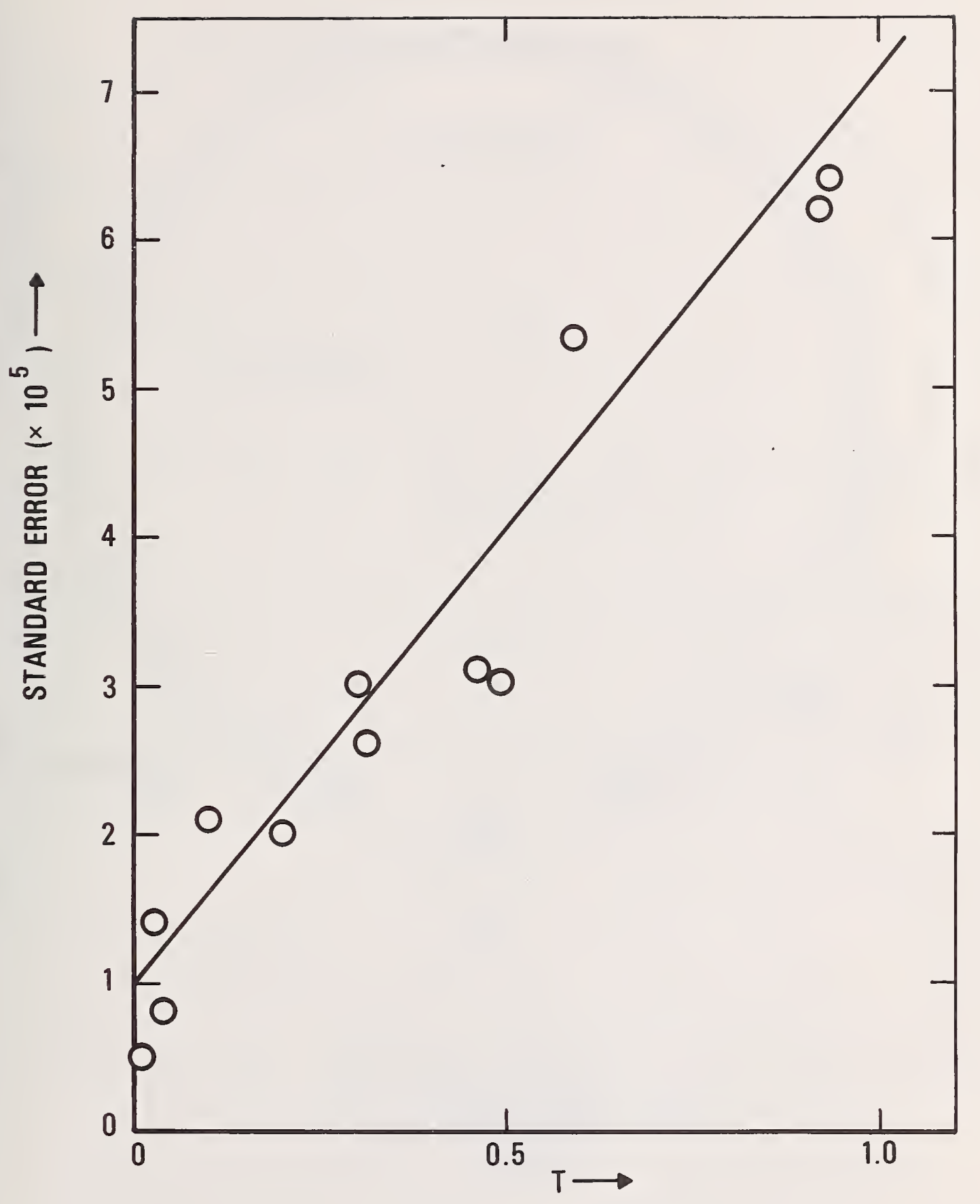

Figure 2: Statistical Uncertainty of Some Measurements as a Function of Transmittance. 


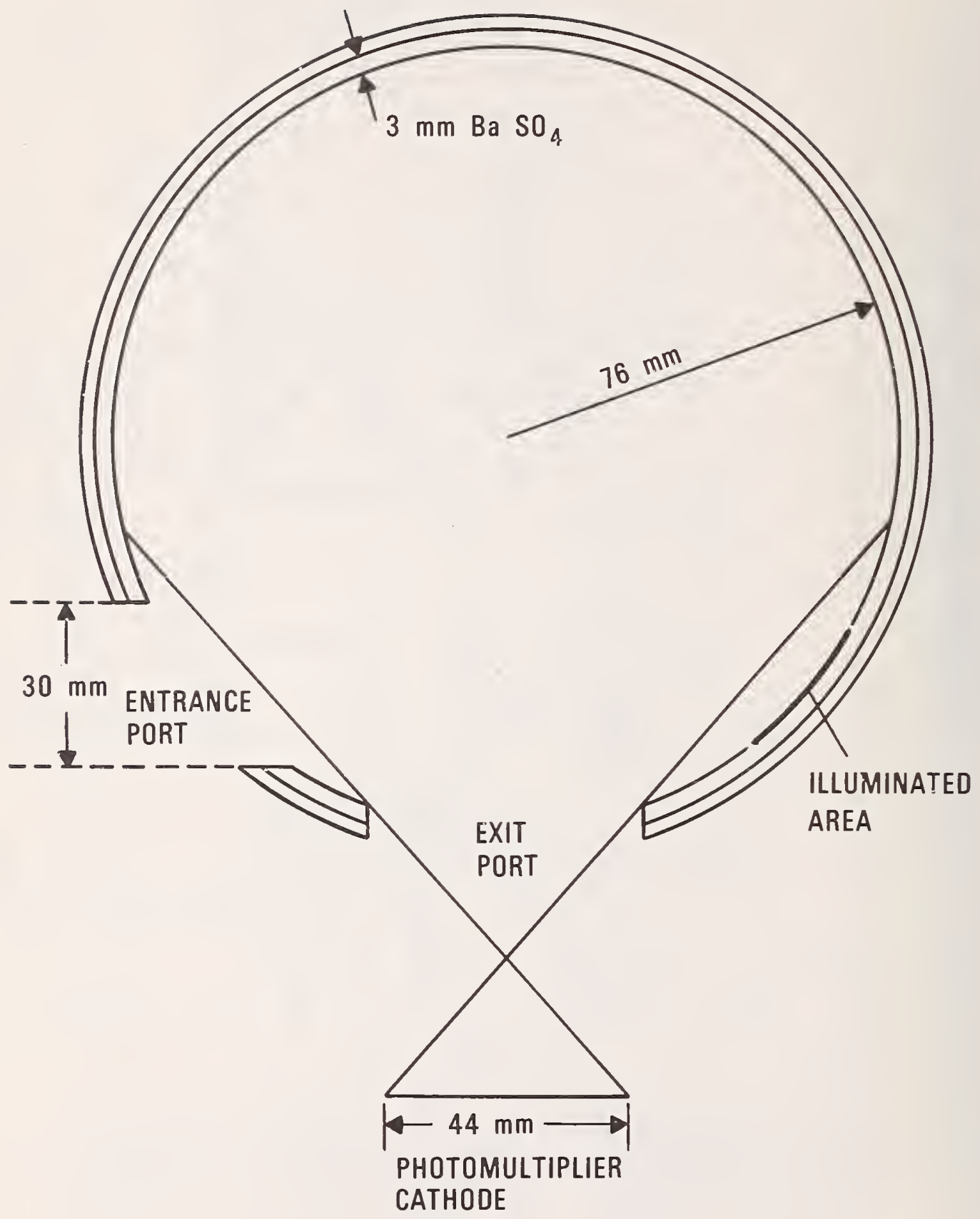

Figure 3: Intermediate Sphere Design Useful in the Visible Spectrum. 

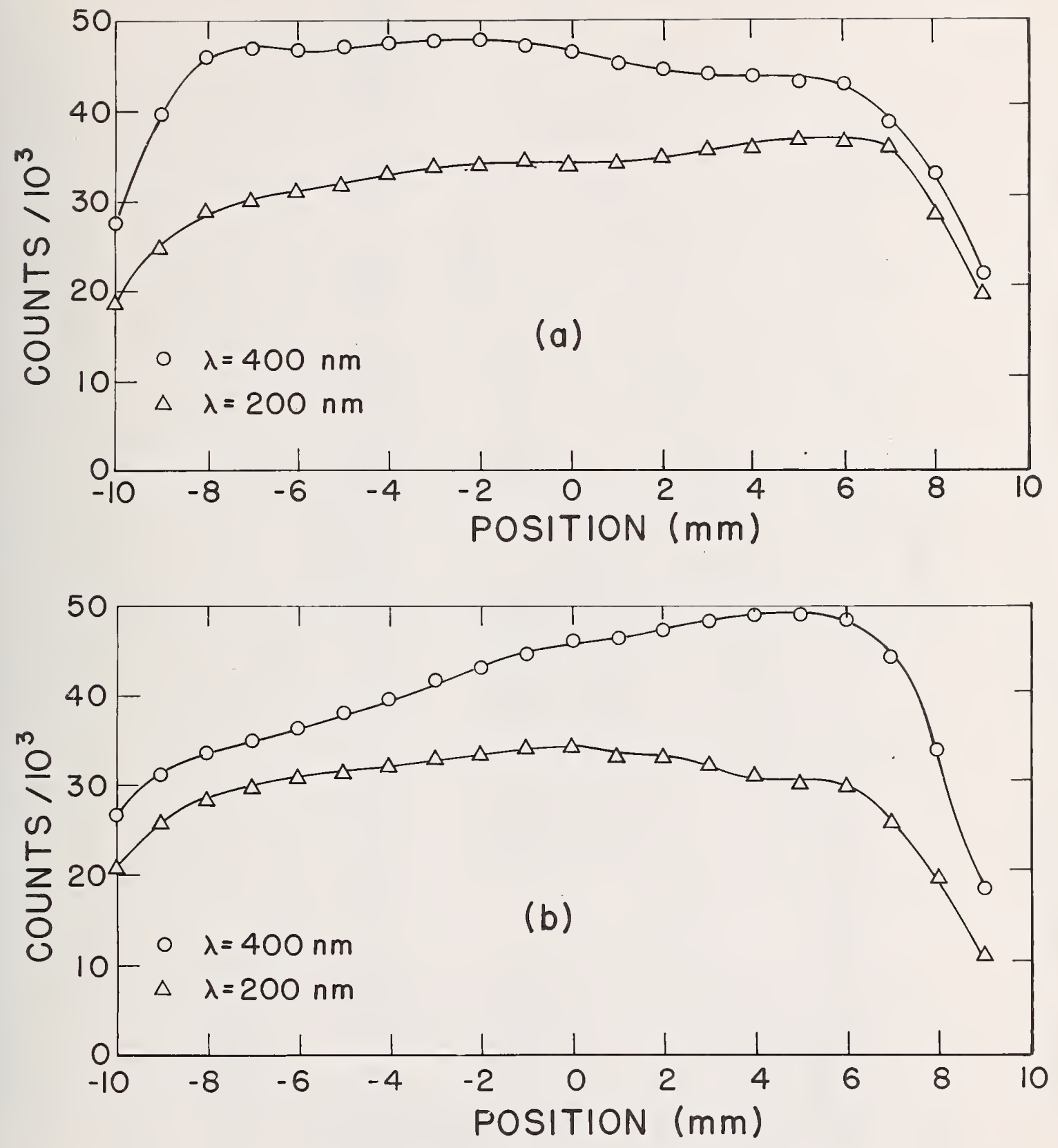

Figure 4: Uniformity of Spectrophotometer Light Beam in Sample Compartment

(a) Scan Parallel to Grating Grooves at $200 \mathrm{~nm}$ and $400 \mathrm{~nm}$.

(b) Scan Perpendicular to Grating Grooves at $200 \mathrm{~nm}$ and $400 \mathrm{~nm}$. 


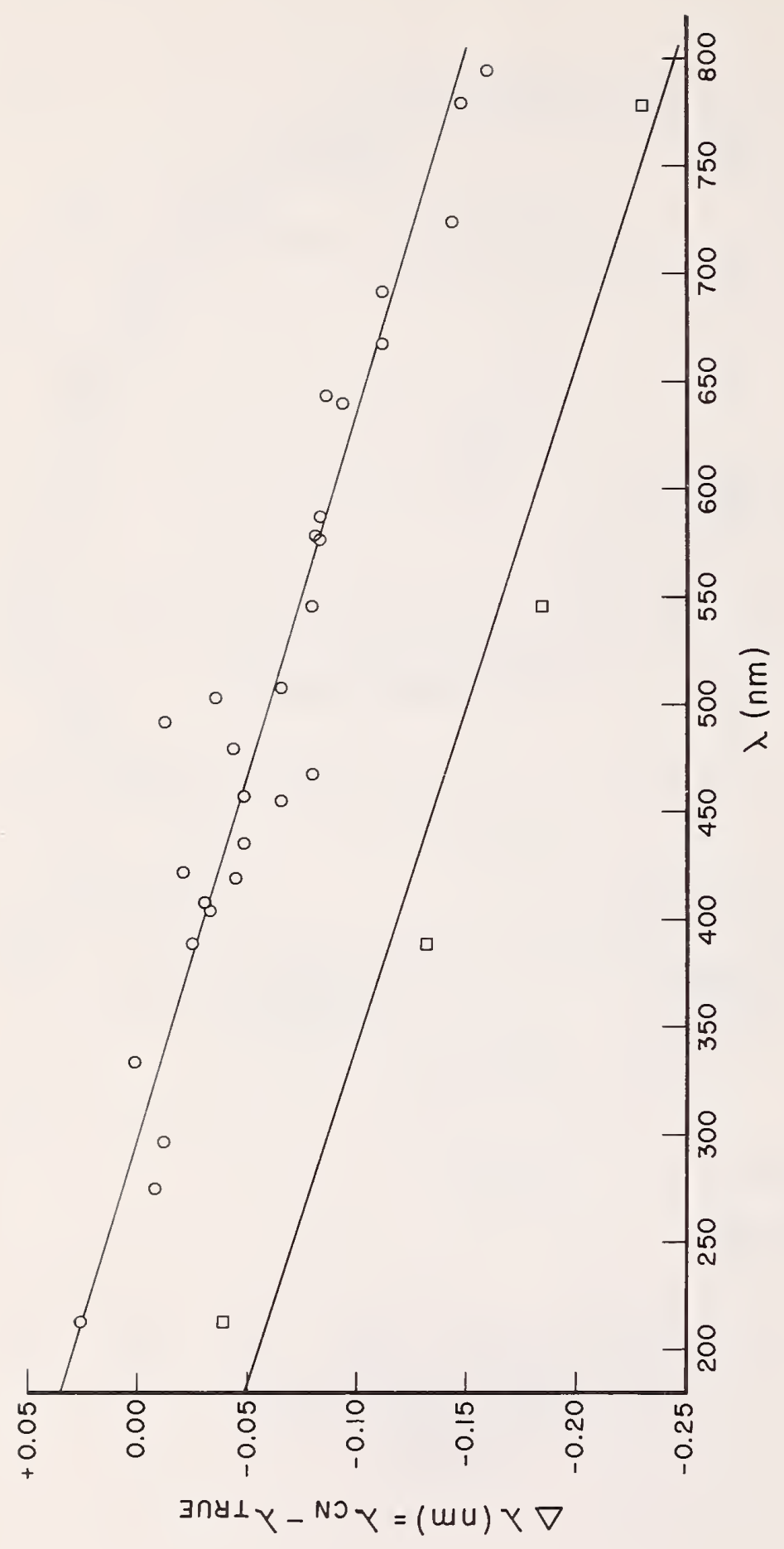

ป⿱一兀) 


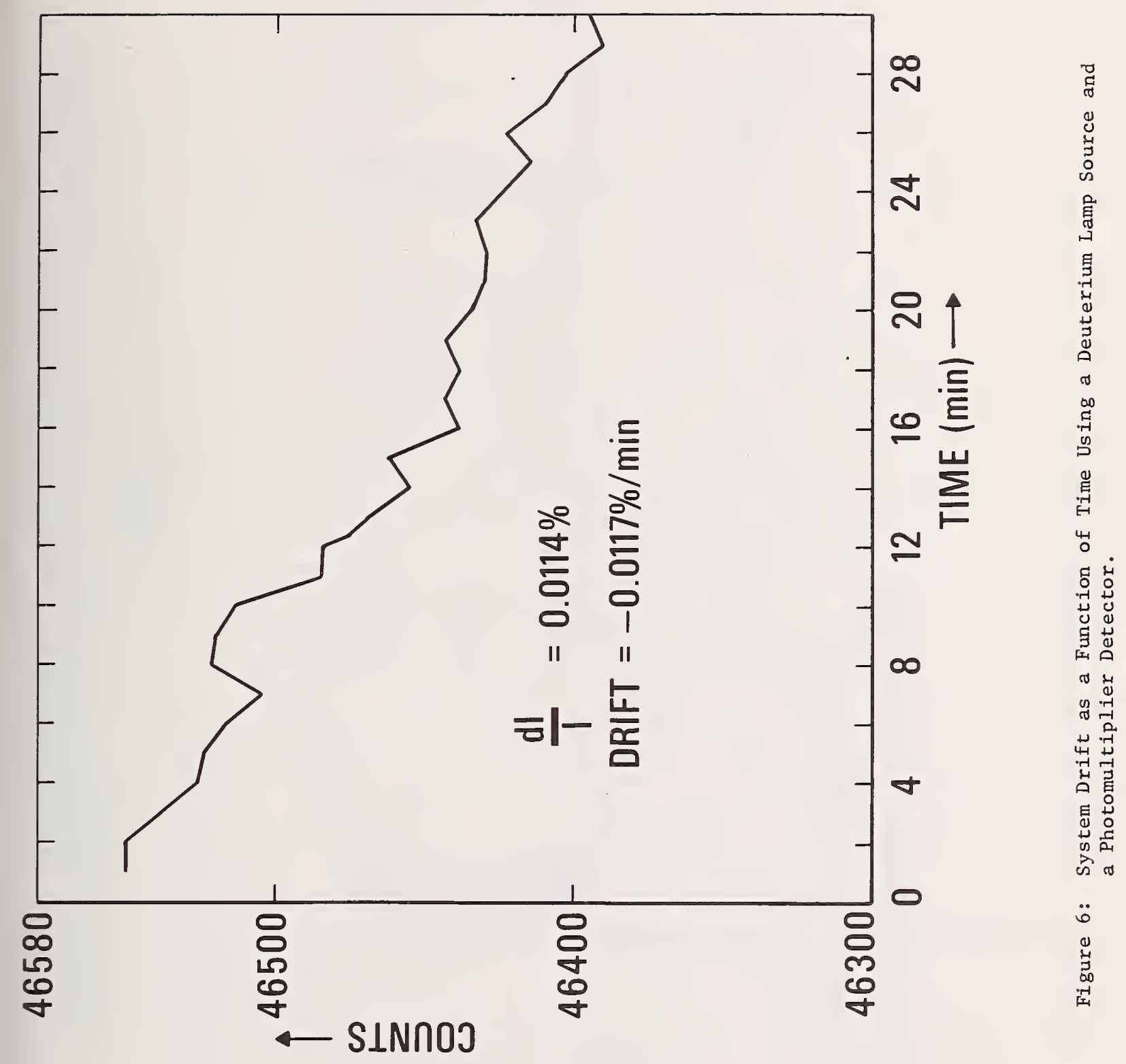




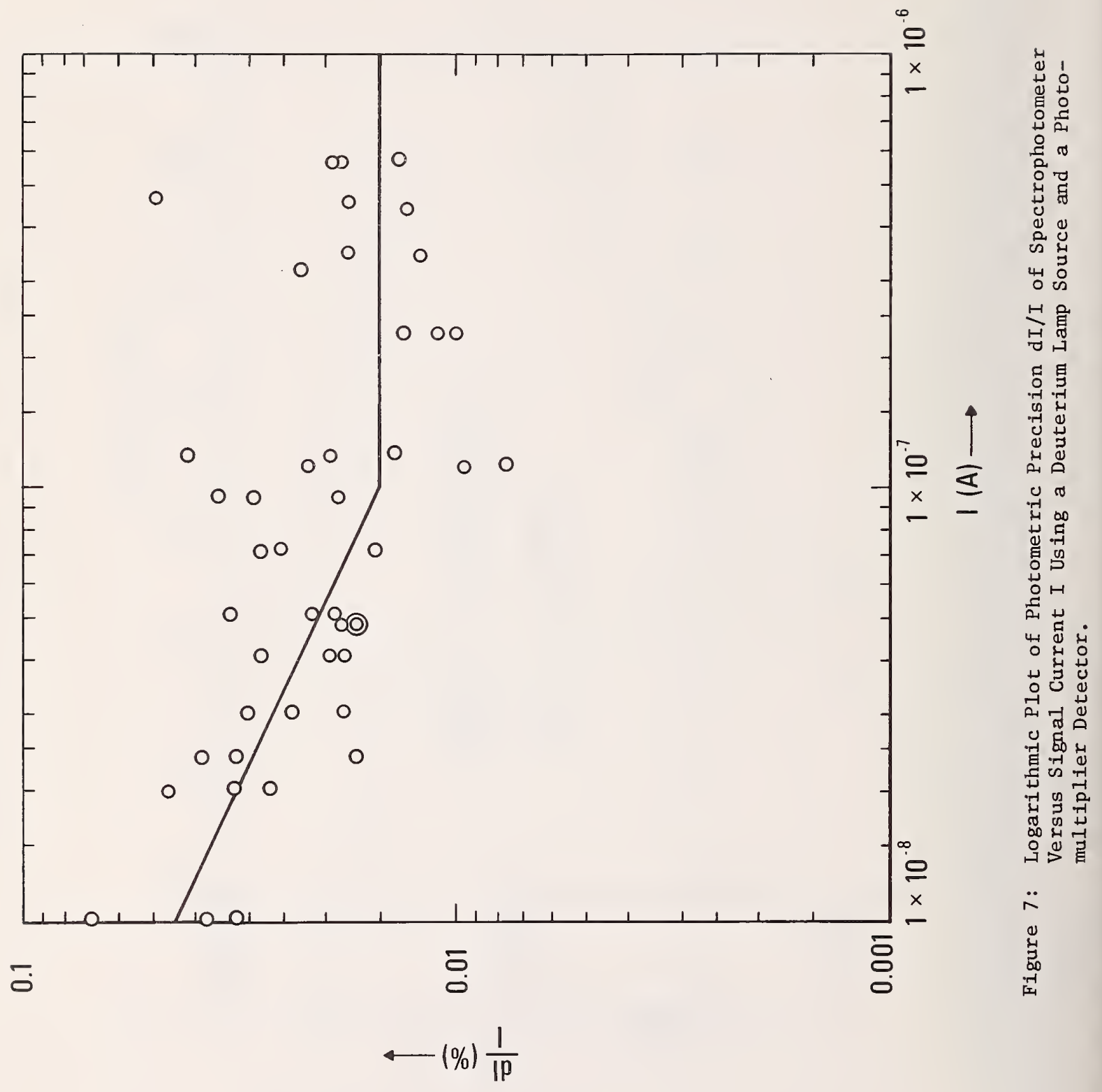




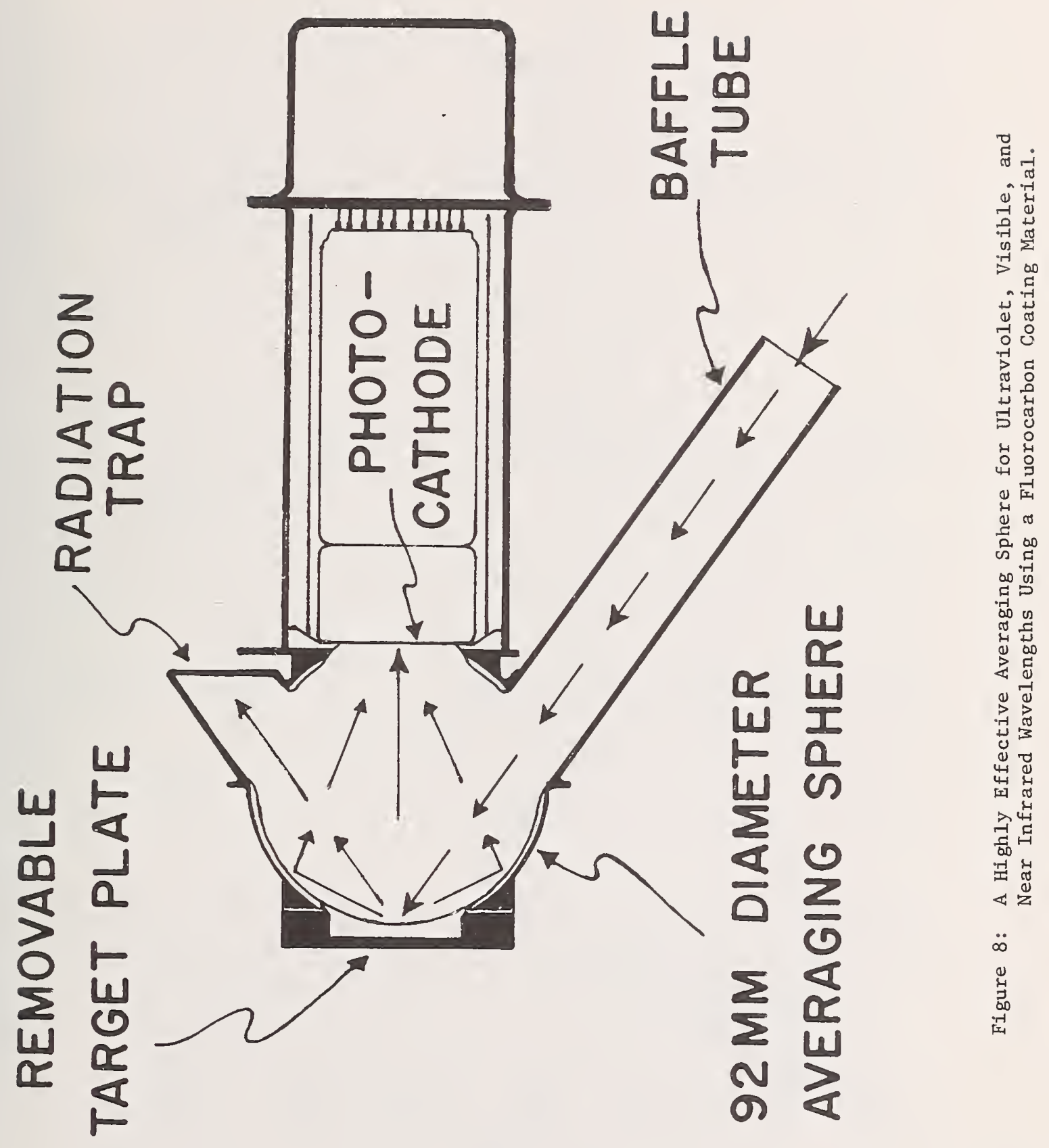




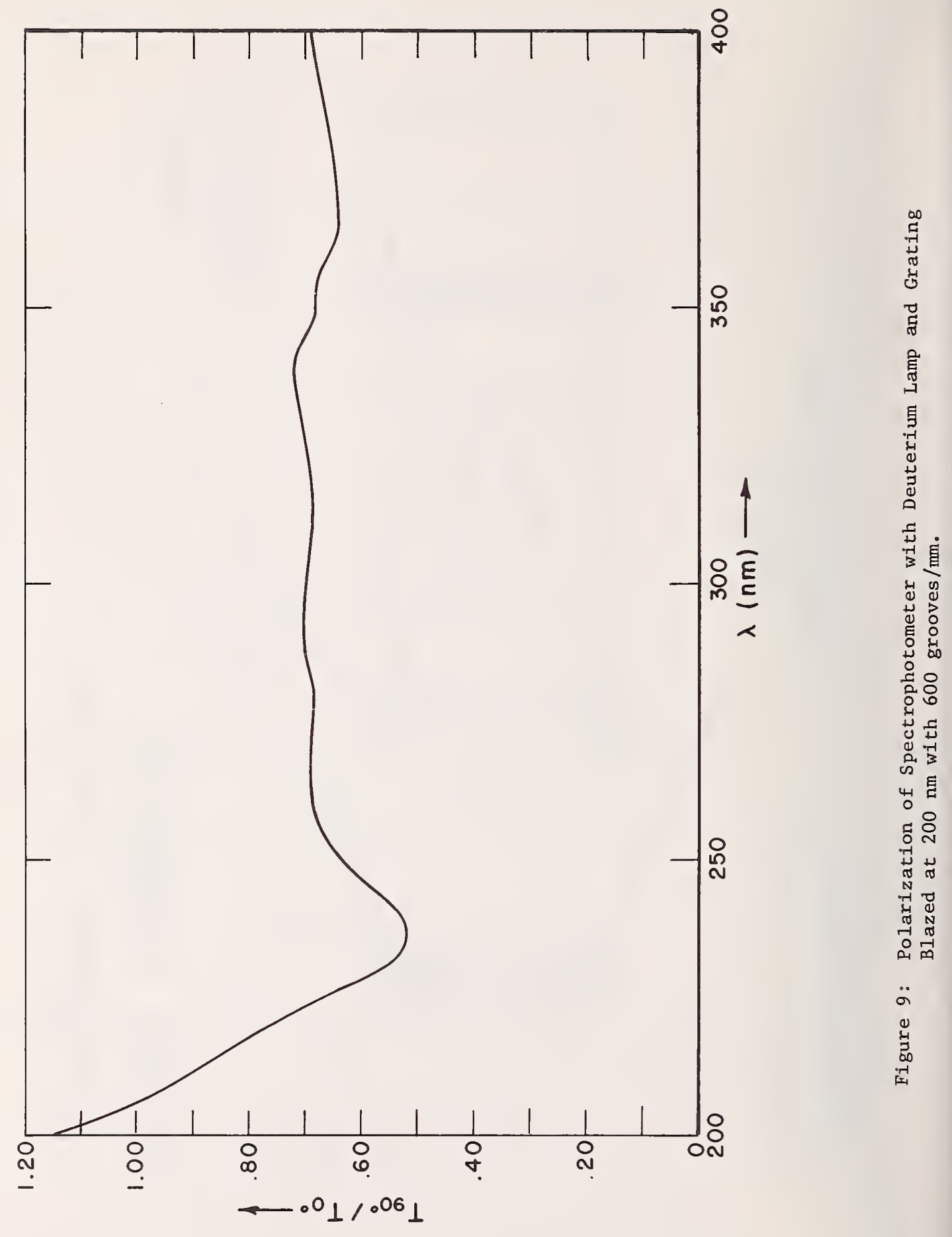



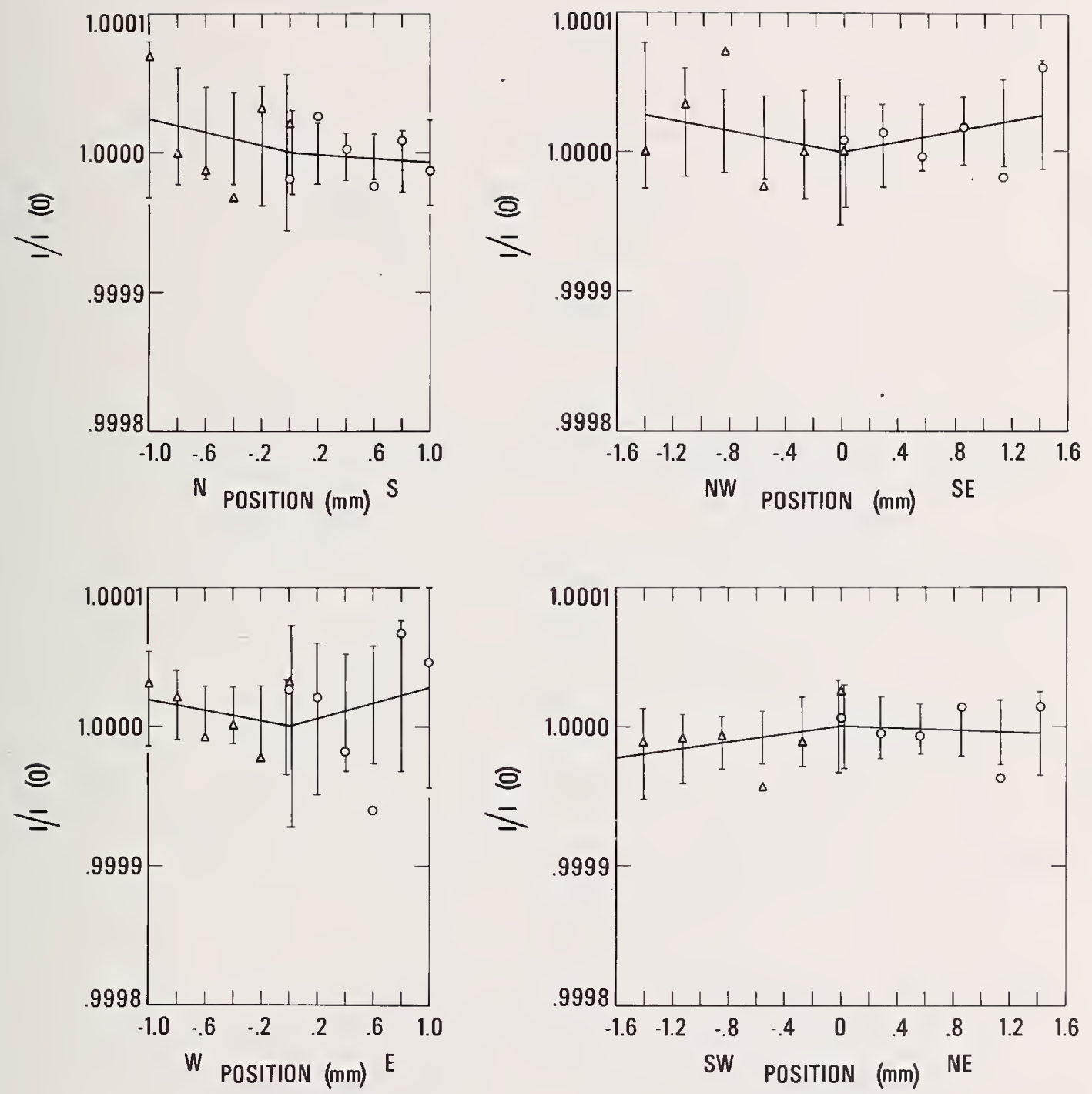

Figure 10: Ratio of Signal I at Various Sphere-Detector Positions to Signal $I(0)$ at the Central Position Normalized as Described in the Text for Tritium Activated Phosphor Attached to the Sphere and Detector. 

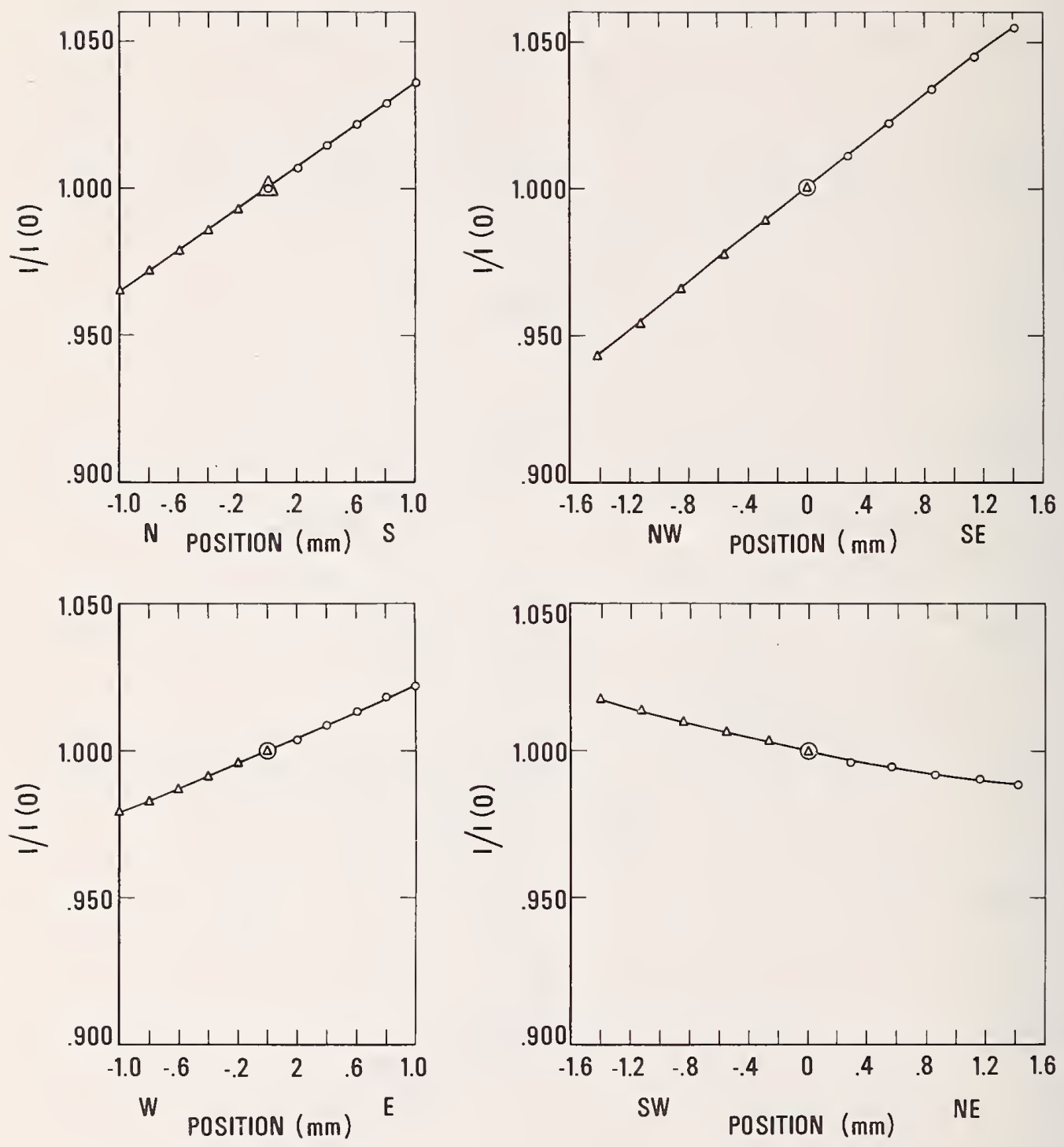

Figure 11: Ratio of Signal I at Various Sphere-Detector Positions to Signal $I(0)$ at the Central Position Normalized as Described in the Text for Bare End-on Photomultiplier. 

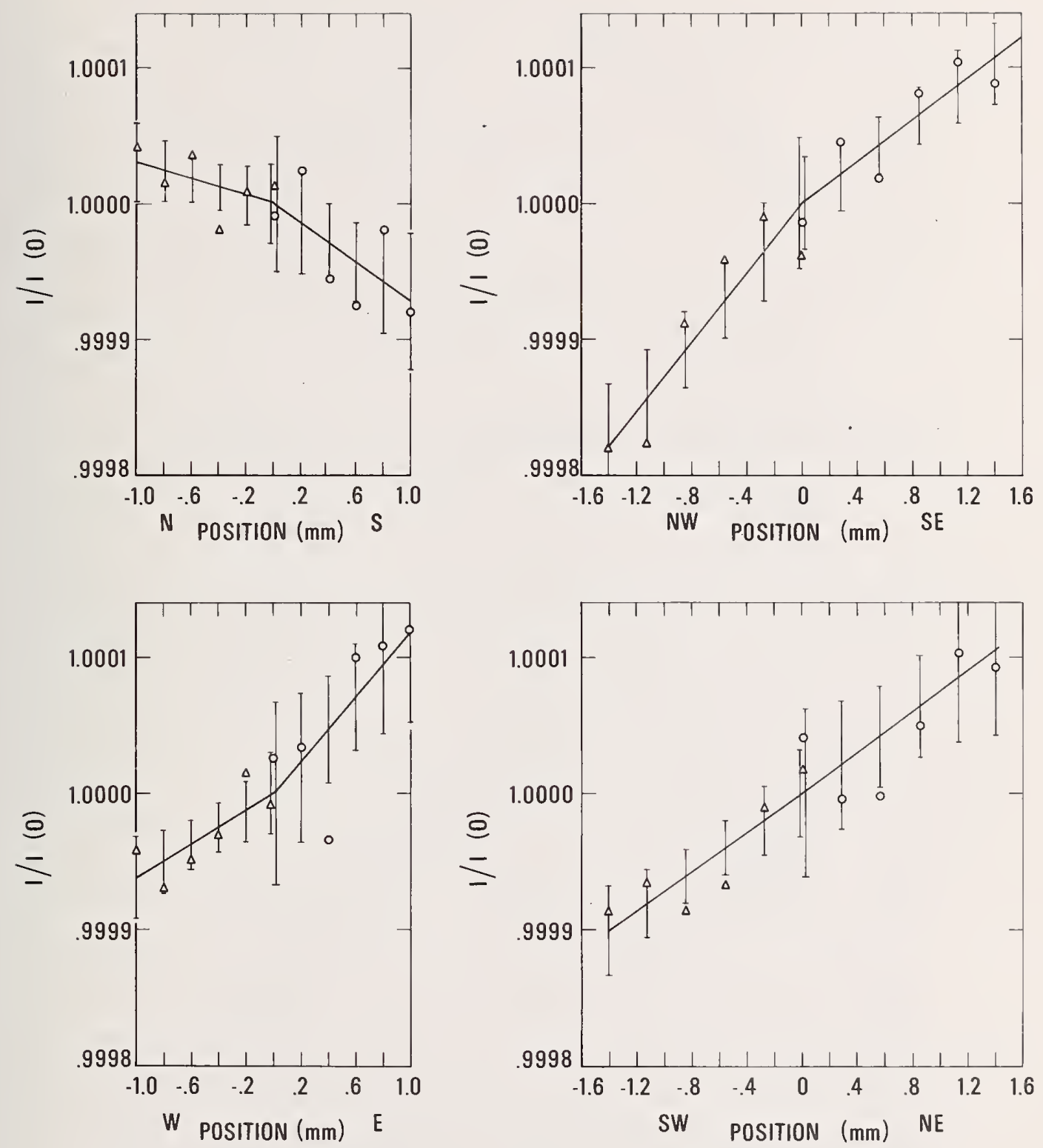

Figure 12: Ratio of Signal I at Varfous Sphere-Detector Positions to Signal $I(0)$ at the Central Position Normalized as Described in the Text for our Intermediate Sphere shown in Figure 3. 

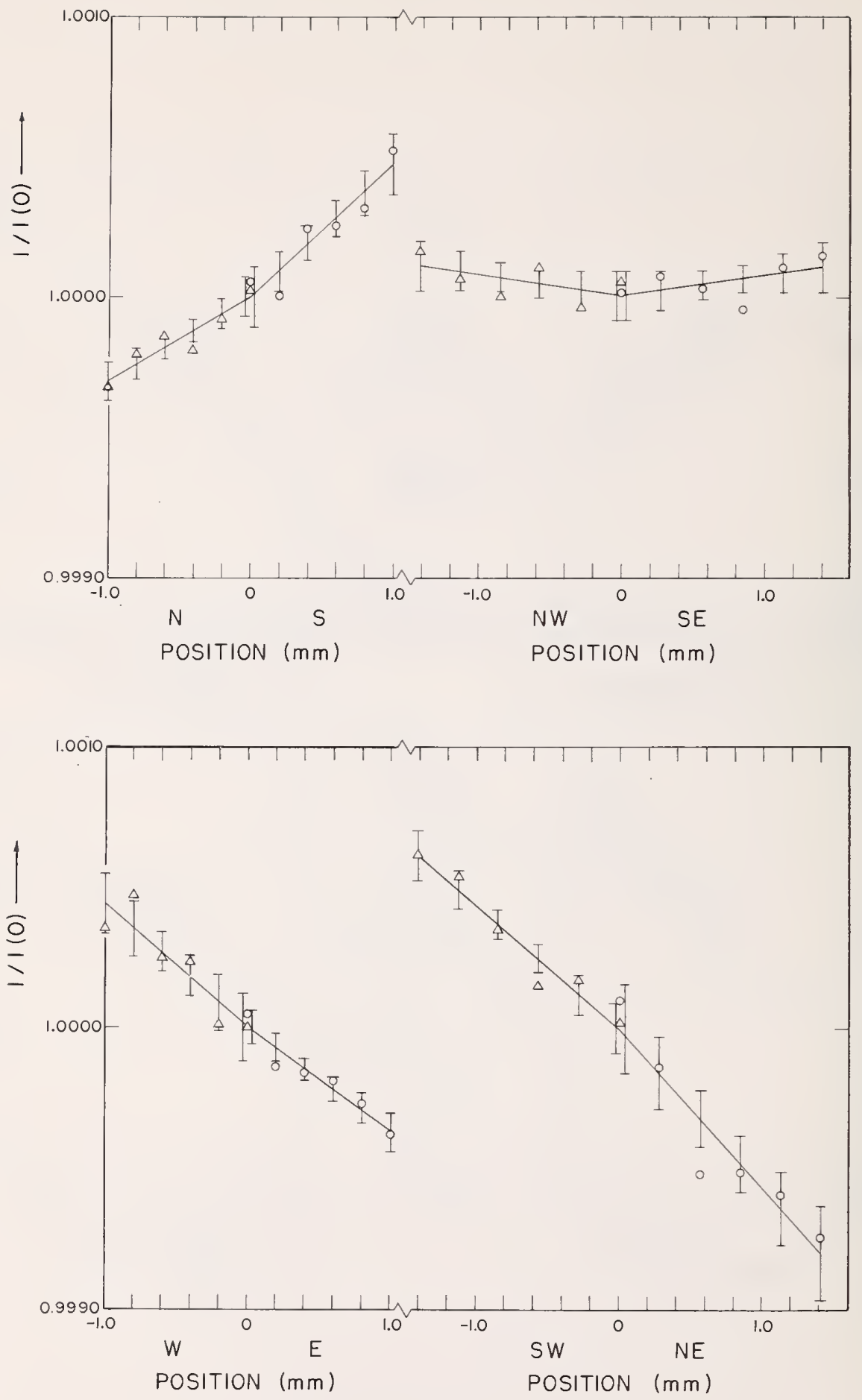

Figure 13: Ratio of Signal I at Various Sphere-Detector Positions to Signal $I(0)$ at the Central Position Normalized as Described in the Text for Fluorocarbon Coated Sphere shown in Figure 8 with Wavelength $250 \mathrm{~nm}$. 

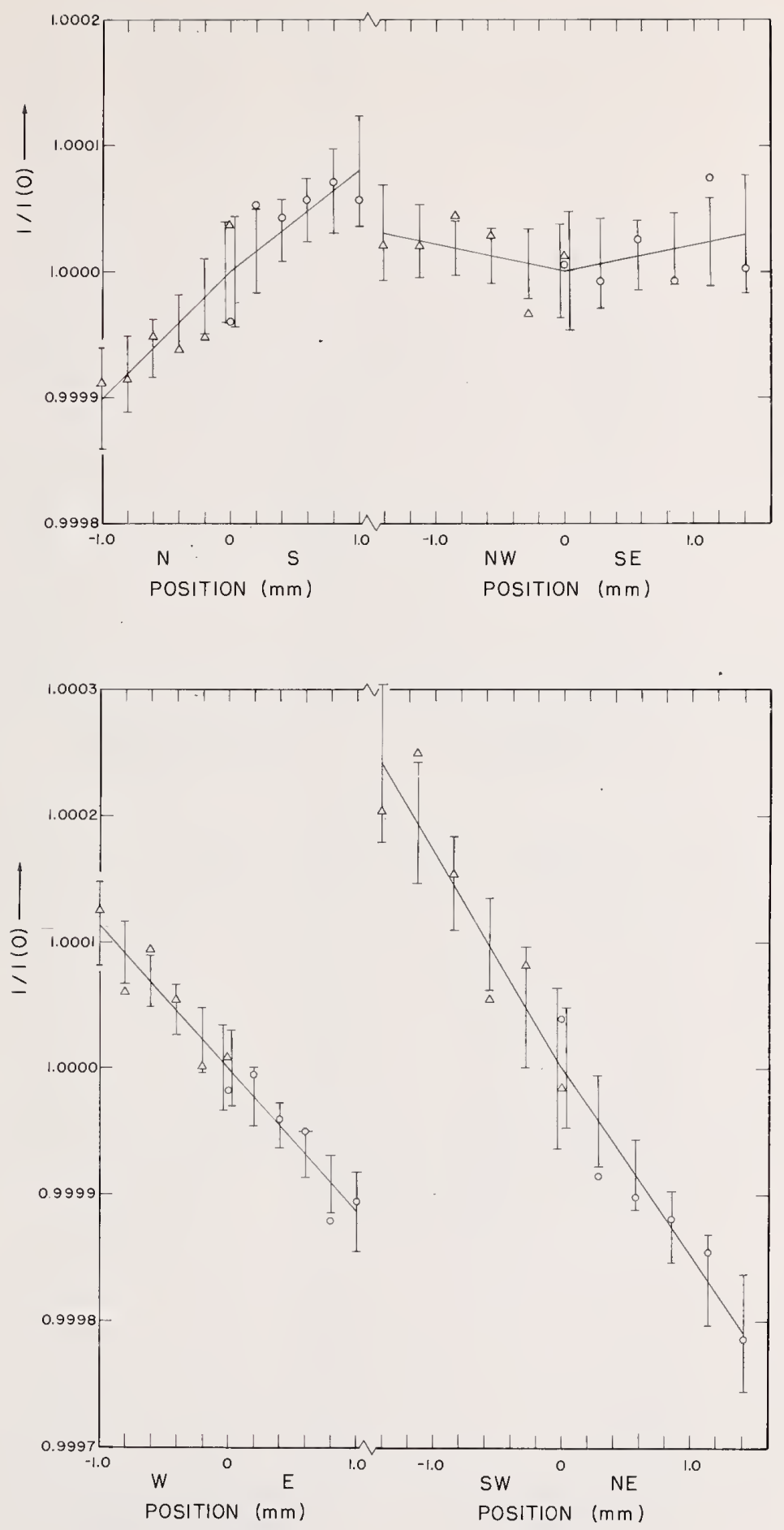

Figure 14: Ratio of Signal I at Various Sphere-Detector Positions to Signal $I(0)$ at the Central Position Normalized as Described in the Text for Fluorocarbon Coated Sphere shown in Figure 8 with Wavelength $525 \mathrm{~nm}$. 

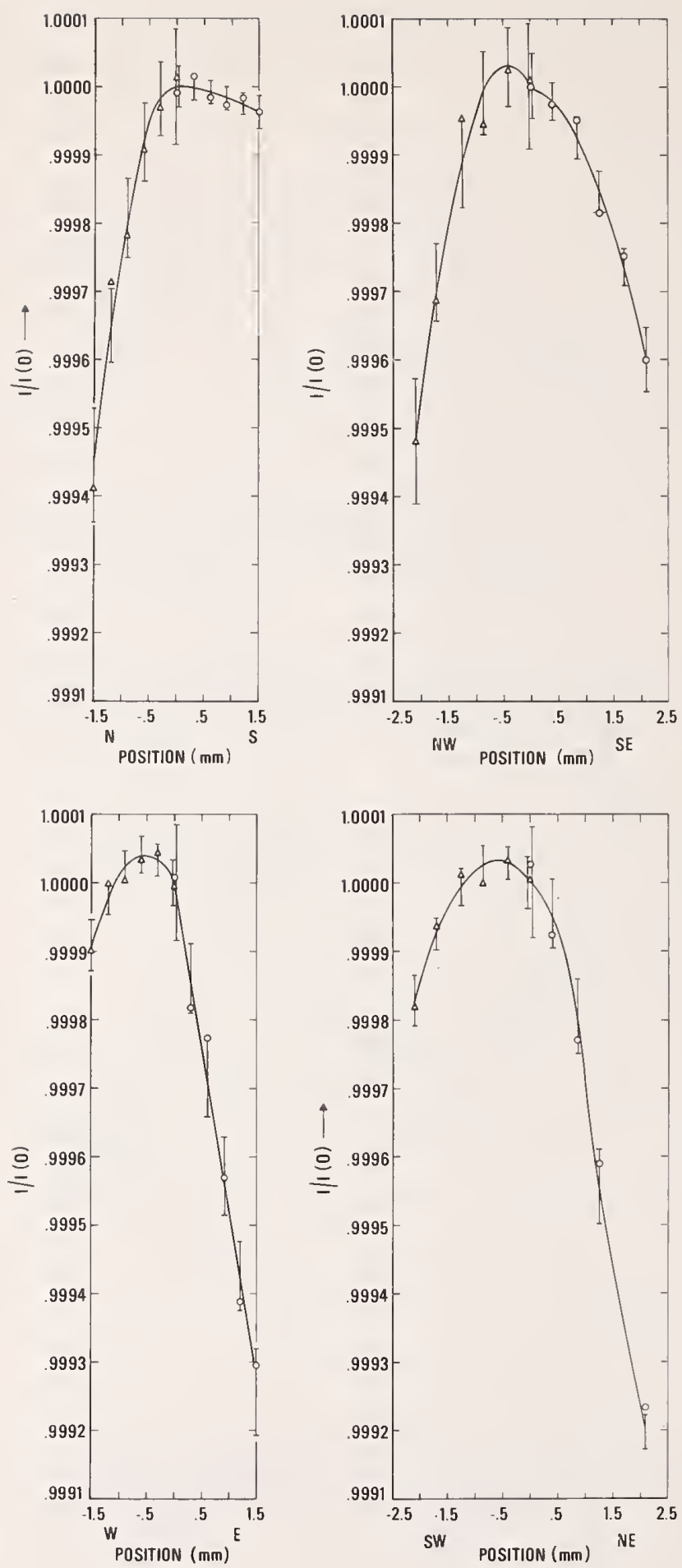

Figure 15: Ratio of Signal I at Various Sphere-Detector Positions to Signal $I(0)$ at the Central Position Normalized as Described in the Text for Sphere with $\mathrm{BaSO}_{4}$ Target. 

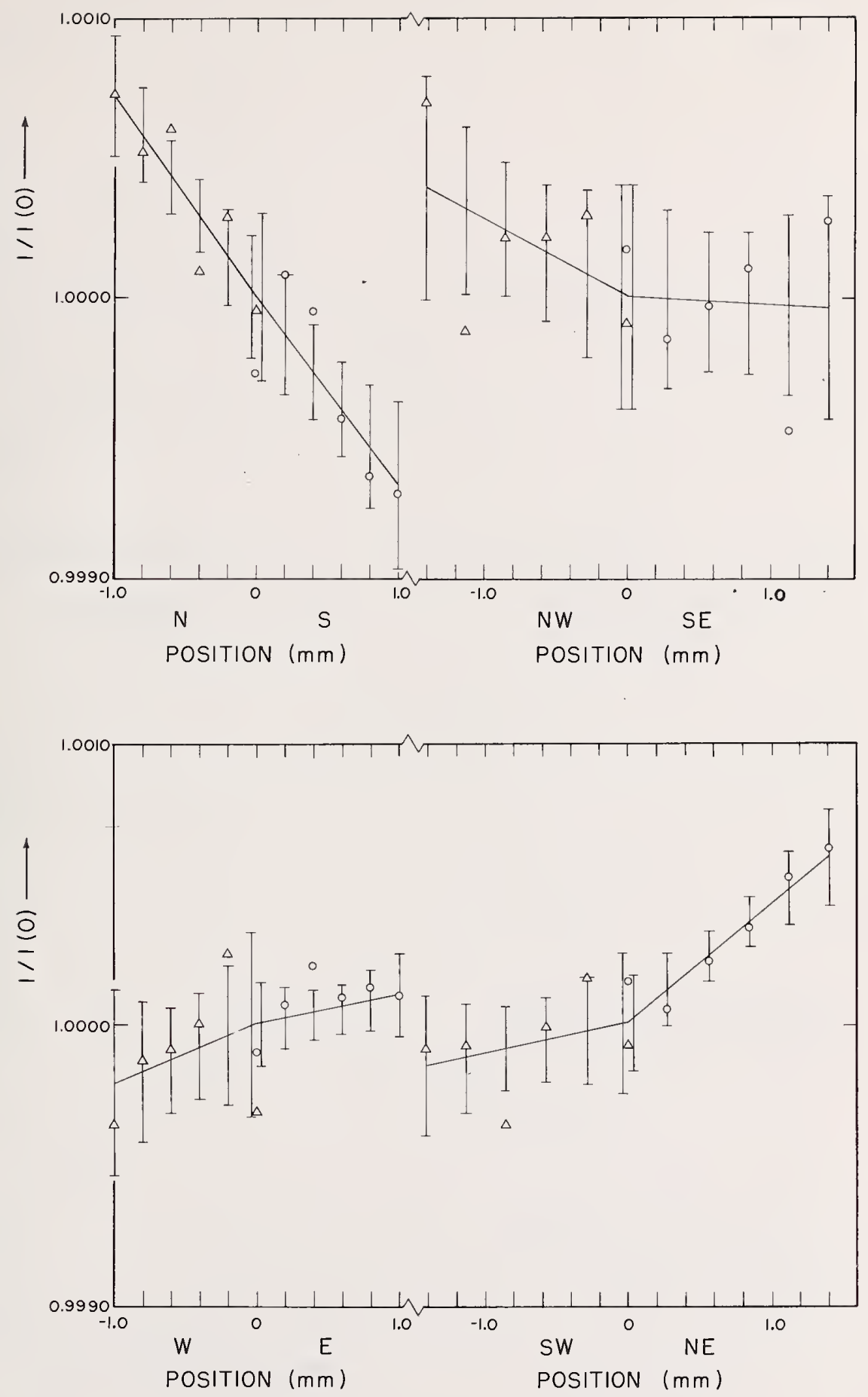

Figure 16: Ratio of Signal I at Various Sphere-Detector Positions to Signal $I(0)$ at the Central Position Normalized as Described in the Text for Sphere with F1uorescent Target with Wavelength $250 \mathrm{~nm}$. 

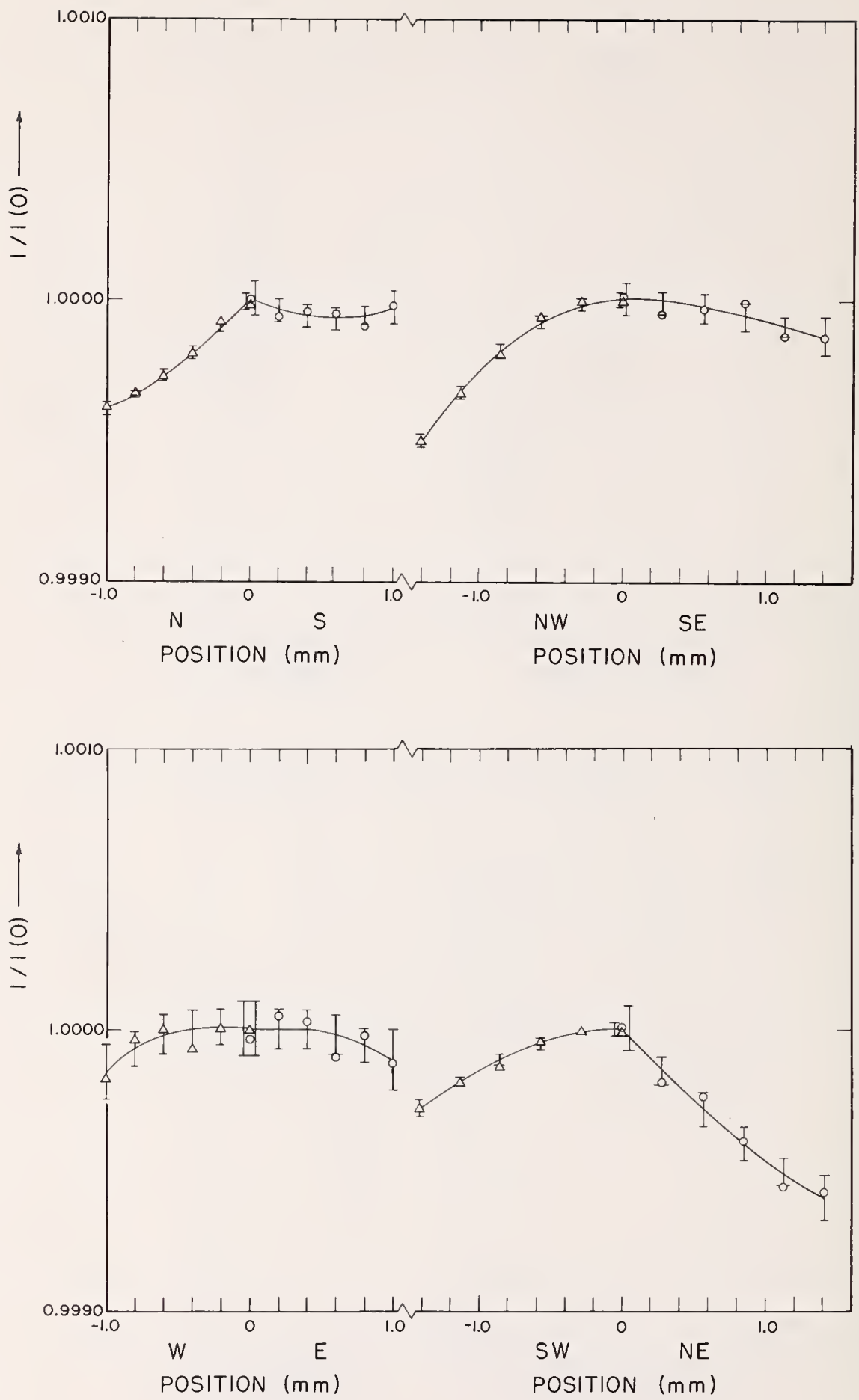

Figure 17: Ratio of Signal I at Various Sphere-Detector Positions to Signal $I(0)$ at the Central Position Normalized as Described in the Text for Sphere with Fluorescent Target with Wavelength $525 \mathrm{~nm}$. 

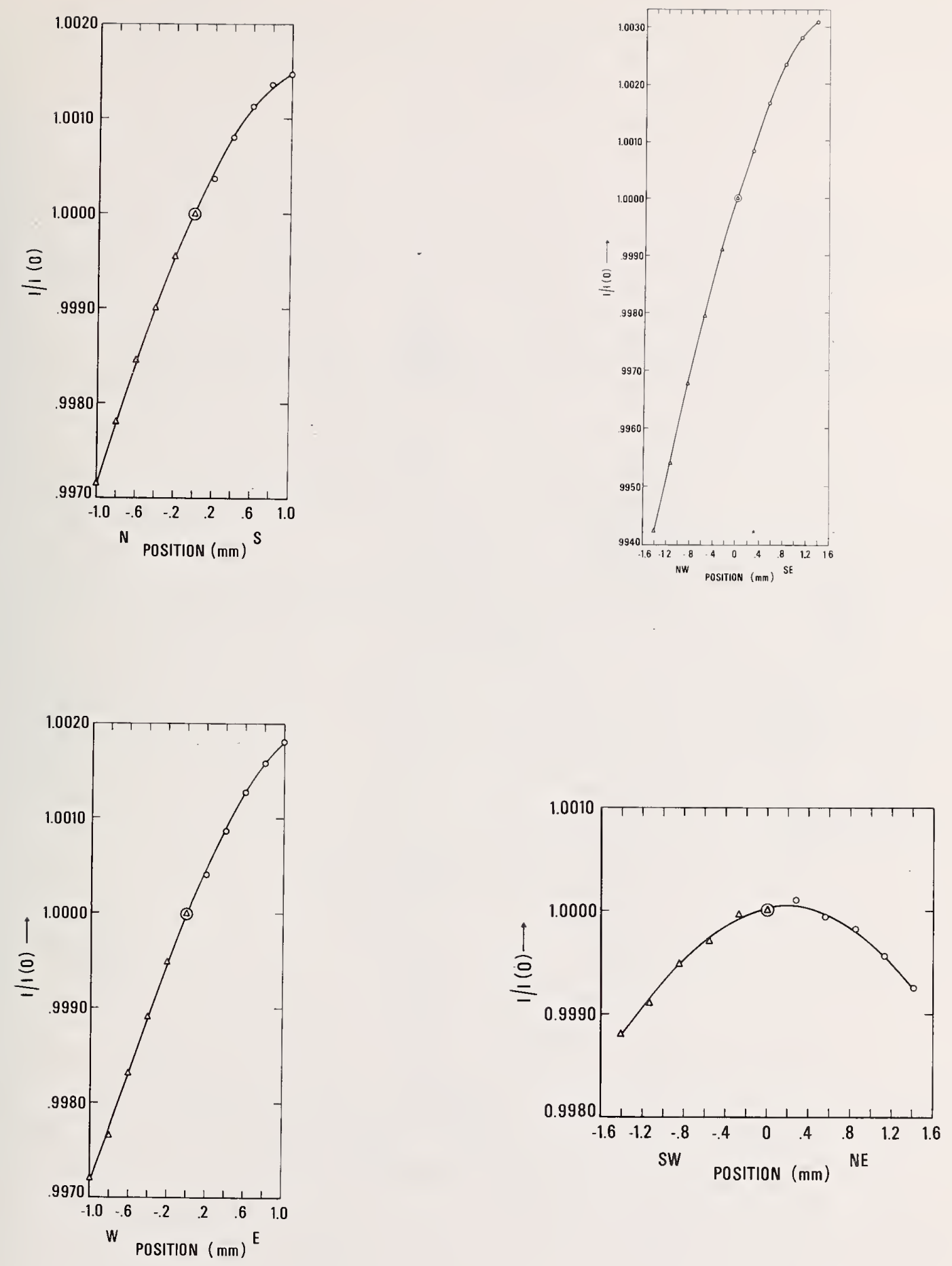

Figure 18: Ratio of Signal I at Various Sphere-Detector Positions to Signal. $I(0)$ at the Central Position Normalized as Described in the Text for Averager Using Ground Quartz Discs at Both Ends of a Diffusing Tube. 

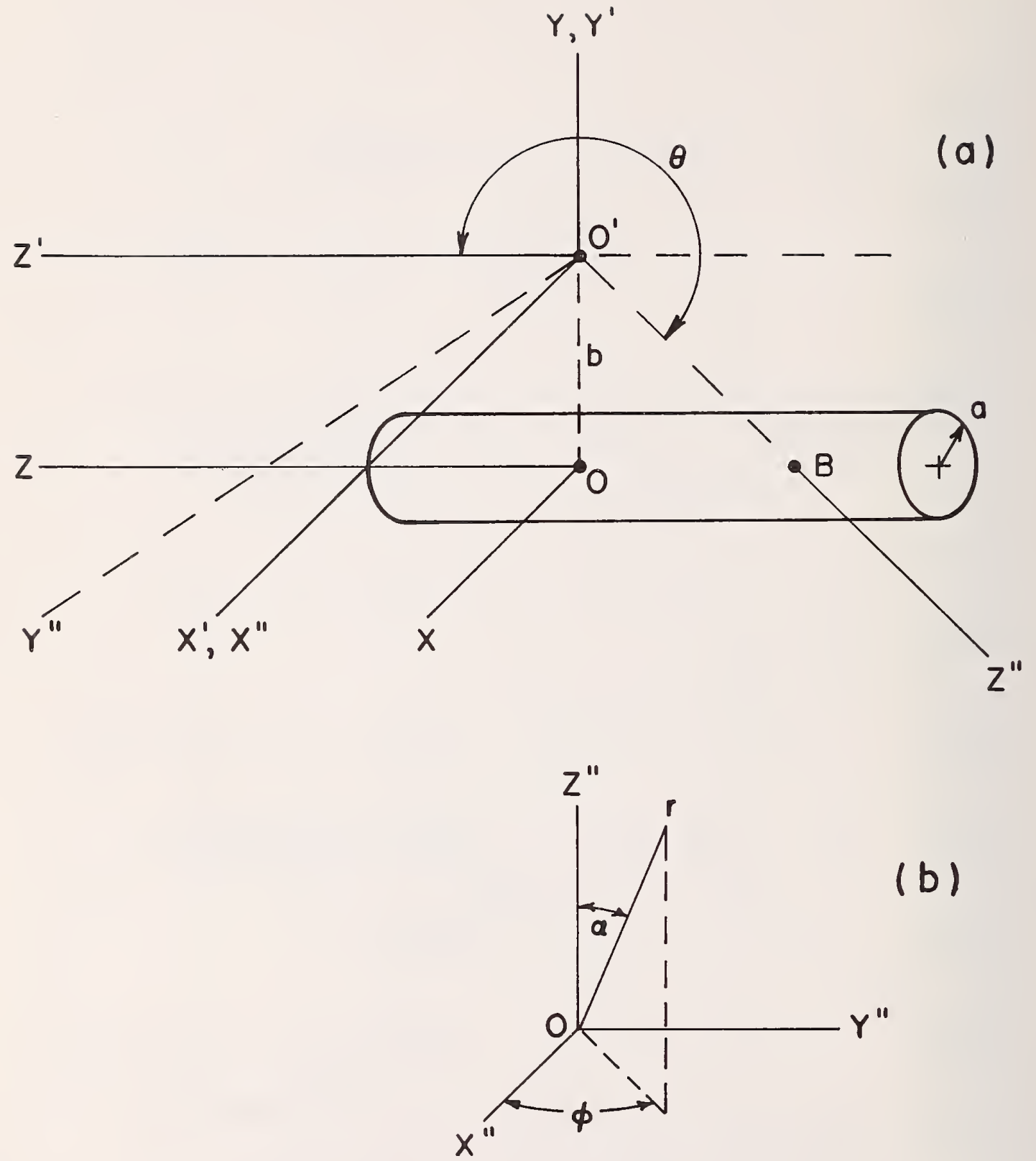

(b)

Figure 19: Geometry Used for Calculations in Appendix A. 

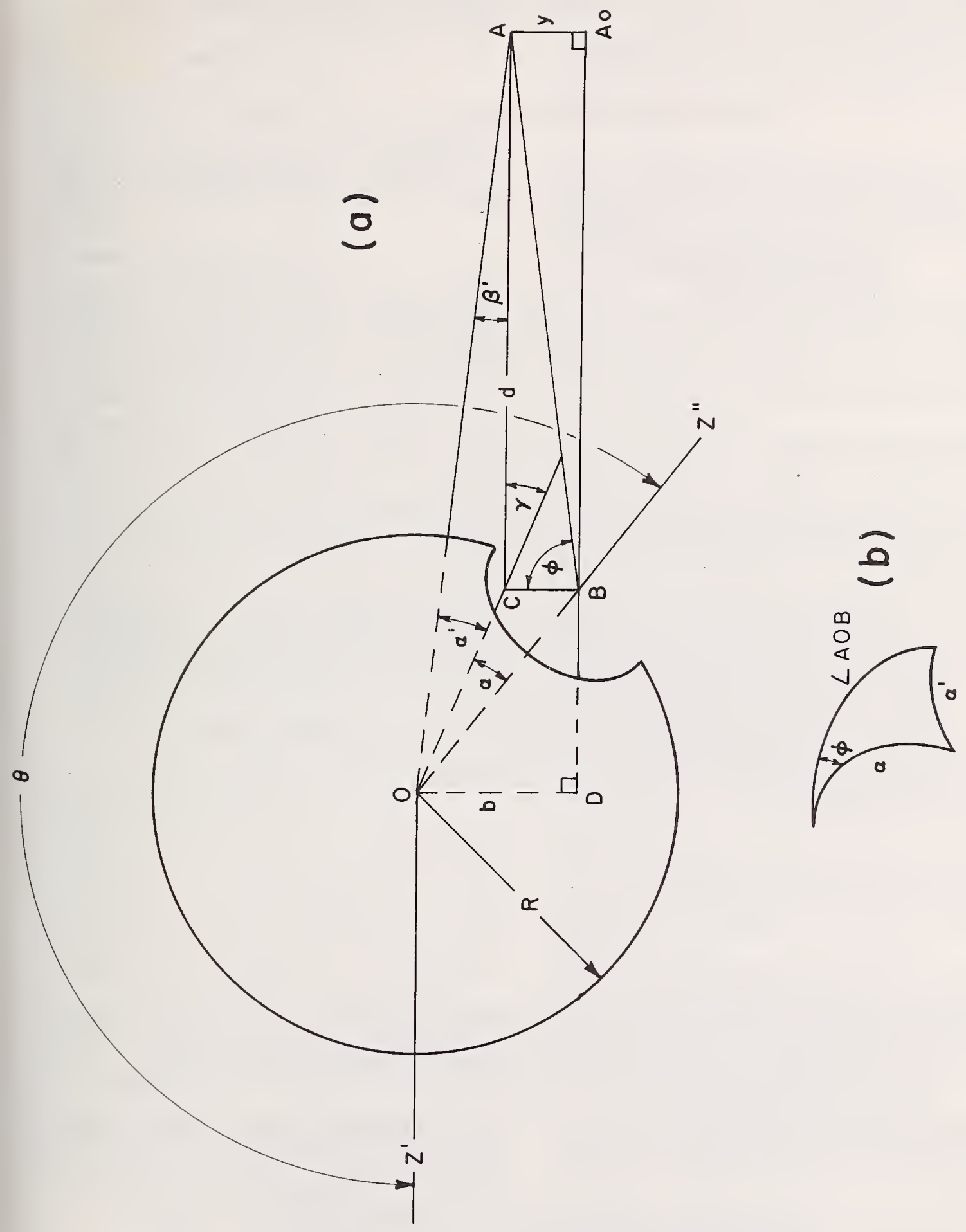

年 
NBS-174A TREV. 7-73)

\begin{tabular}{|c|c|c|}
\hline $\begin{array}{c}\text { 1. PUBLICATION OR REPORT NO. } \\
N B S T N-913\end{array}$ & $\begin{array}{l}\text { 2. Gov't Accession } \\
\text { No. }\end{array}$ & 3. Recipient's Accession No. \\
\hline \multirow{2}{*}{\multicolumn{2}{|c|}{ Modification of an NBS Reference Spectrophotometer }} & $\begin{array}{r}\text { 5. Publication Date } \\
\text { July } 1976\end{array}$ \\
\hline & & 6. Performing Organization Code \\
\hline \multicolumn{2}{|l|}{ Kenneth L. Eckerle } & 8. Performing Organ. Report No. \\
\hline \multirow{2}{*}{\multicolumn{2}{|c|}{$\begin{array}{l}\text { 9. PERFORMING ORGANIZATION NAME AND ADDRESS } \\
\text { NATIONAL BUREAU OF STANDARDS } \\
\text { DEPARTMENT OF COMMERCE } \\
\text { WASHINGTON, D.C. } 20234\end{array}$}} & 10. Project/Task/Work Unit No. \\
\hline & & i1. Contract/Grant No. \\
\hline \multirow{2}{*}{\multicolumn{2}{|c|}{ 12. Sponsoring Organization Name and Complete Address (Street, City, State, ZIP) }} & $\begin{array}{l}\text { 13. Type of Report \& Period } \\
\text { Covered } \\
\text { Final }\end{array}$ \\
\hline & & 14. Sponsoring Agency Code \\
\hline
\end{tabular}

15. SUPPLEMENTARY NOTES

16. ABSTRACT (A 200-word or less factual summary of most significant in formation. If document includes a significant bibliography or literature survey, mention it here.)

The description of a new reference spectrophotometer capable of making transmittance measurements accurate to 0.0001 transmittance units has already been reported. The purpose of this publication is to describe some modifications that have been made to this instrument and to report some further measurements performed with it. The extension of the range of the instrument down to $200 \mathrm{~nm}$, providing a capability for making measurements over the spectral range 200 to $800 \mathrm{~nm}$, is outlined, and extensive testing of the light averaging effectiveness of several types of devices and spheres is reported here.

17. KEY WORDS (six to twelve entries; alphabetical order; capitalize only the first letter of the first key word unless a proper name; separated by semicolons)

Averaging spheres; high accuracy transmittance; light averaging devices; linearity; photometric precision; reference spectrophotometer; ultraviolet; wavelength calibration.

18. AVAILABILITY [X] Unlimited

For Official Distribution. Do Not Release to NTIS

\begin{tabular}{|l|l|c|}
\hline $\begin{array}{l}\text { 19. SECURITY CLASS } \\
\text { (THIS REPURT) } \\
\text { UNCLASSIFIED }\end{array}$ & 21. NO. OF PAGES \\
\hline $\begin{array}{l}\text { 20. SECURITY CLASS } \\
\text { (THIS PAGE) } \\
\text { UNCLASSIFIED }\end{array}$ & $\begin{array}{l}\text { 22. Price } \\
\$ 1.00\end{array}$ \\
\hline
\end{tabular}

21. NO. OF PAGES

[X] Order From Sup, of Doc., U.S. Government Printing Office Washington, D.C. 20402, SD Cat. No. C13.46:913

Order From National Technical Information Service (NTIS) Springfield, Virginia 22151 


\section{PERIODICALS}

JOURNAL OF RESEARCH reports National Bureau of Standards research and development in physics, mathematics, and chemistry. It is published in two sections, available separately:

- Physics and Chemistry (Section A)

Papers of interest primarily to scientists working in these fields. This section covers a broad range of physical and chemical research, with major emphasis on standards of physical measurement, fundamental constants, and properties of matter. Issued six times a year. Annual subscription: Domestic, \$17.00; Foreign, $\$ 21.25$.

\section{- Mathematical Sciences (Section B)}

Studies and compilations designed mainly for the mathematician and theoretical physicist. Topics in mathematical statistics, theory of experiment design, numerical analysis, theoretical physics and chemistry, logical design and programming of computers and computer systems. Short numerical tables. Issued quarterly. Annual subscription: Domestic, $\$ 9.00$; Foreign, $\$ 11.25$.

DIMENSIONS/NBS (formerly Technical News Bulletin)-This monthly magazine is published to inform scientists, engineers, businessmen, industry, teachers, students, and consumers of the latest advances in science and technology, with primary emphasis on the work at NBS. The magazine highlights and reviews such issues as energy research, fire protection, building tech. nology, metric conversion, pollution abatement, health and safety, and consumer product performance. In addition, it reports the results of Bureau programs in measurement standards and techniques, properties of matter and materials, engineering standards and services, instrumentation, and automatic data processing.

Annual subscription: Domestic, \$9.45; Foreign, \$11.85.

\section{NONPERIODICALS}

Monographs-Major contributions to the technical literature on various subjects related to the Bureau's scientific and technical activities.

Handbooks-Recommended codes of engineering and industrial practice (including safety codes) developed in cooperation with interested industries, professional organizations, and regulatory bodies.

Special Publications-Include proceedings of conferences sponsored by NBS, NBS annual reports, and other special publications appropriate to this grouping such as wall charts, pocket cards, and bibliographies.

Applied Mathematics Series-Mathematical tables, manuals, and studies of special interest to physicists, engineers, chemists, biologists, mathematicians, computer programmers, and others engaged in scientific and technical work.

National Standard Reference Data Series-Provides quantitative data on the physical and chemical properties of materials, compiled from the world's literature and critically evaluated. Developed under a world-wide program coordinated by NBS. Program under authority of National Standard Data Act (Public Law 90-396).

NOTE: At present the principal publication outlet for these data is the Journal of Physical and Chemical Reference Data (JPCRD) published quarterly for NBS by the American Chemical Society (ACS) and the American Institute of Physics (AIP). Subscriptions, reprints, and supplements available from ACS, 1155 Sixteenth St. N. W., Wash. D. C. 20056.

Building Science Series-Disseminates technical information developed at the Bureau on building materials, components, systems, and whole structures. The series presents research results, test methods, and performance criteria related to the structural and environmental functions and the durability and safety characteristics of building elements and systems.

Technical Notes-Studies or reports which are complete in themselves but restrictive in their treatment of a subject. Analogous to monographs but not so comprehensive in scope or definitive in treatment of the subject area. Often serve as a vehicle for final reports of work performed at NBS under the sponsorship of other government agencies.

Voluntary Product Standards-Developed under procedures published by the Department of Commerce in Part 10, Title 15, of the Code of Federal Regulations. The purpose of the standards is to establish nationally recognized requirements for products, and to provide all concerned interests with a basis for common understanding of the characteristics of the products. NBS administers this program as a supplement to the activities of the private sector standardizing organizations.

Federal Information Processing Standards Publications (FIPS PUBS)-Publications in this series collectively constitute the Federal Information Processing Standards Register. Register serves as the official source of information in the Federal Government regarding standards issued by NBS pursuant to the Federal Property and Administrative Services Act of 1949 as amended, Public Law 89-306 (79 Stat. 1127), and as implemented by Executive Order 11717 (38 FR 12315, dated May 11, 1973) and Part 6 of Title 15 CFR (Code of Federal Regulations).

Consumer Information Series-Practical information, based on NBS research and experience, covering areas of interest to the consumer. Easily understandable language and illustrations provide useful background knowledge for shopping in today's technological marketplace.

NBS Interagency Reports (NBSIR)-A special series of interim or final reports on work performed by NBS for outside sponsors (both government and non-government). In general, initial distribution is handled by the sponsor; public distribution is by the National Technical Information Service (Springfield, Va. 22161) in paper copy or microfiche form.

Order NBS publications (except NBSIR's and Bibliographic Subscription Services) from: Superintendent of Documents, Government Printing Office, Washington, D.C. 20402.

\section{BIBLIOGRAPHIC SUBSCRIPTION SERVICES}

The following current-awareness and literature-survey bibliographies are issued periodically by the Bureau: Cryogenic Data Center Current Awareness Service

A literature survey issued biweekly. Annual subscription: Domestic, $\$ 20.00$; foreign, $\$ 25.00$.

Liquefied Natural Gas. A literature survey issued quarterly. Annual subscription: $\$ 20.00$.

Superconducting Devices and Materials. A literature survey issued quarterly. Annual subscription: $\$ 20.00$ Send subscription orders and remittances for the preceding bibliographic services to National Bureau of Standards, Cryogenic Data Center (275.02) Boulder, Colorado 80302 .

Electromagnetic Metrology Current Awareness Service Issued monthly. Annual subscription: \$24.00. Send subscription order and remittance to Electromagnetics Division, National Bureau of Standards, Boulder, Colo. 80302 . 
U.S. DEPARTMENT OF COMAERCE

National Bureau of Standards

Washington, D.C. 20234

POSTAEE ANO FEES PAID

U.S. DEPARTMENT OF COMMERCE

$C O M-215$

Penalty for Private Use, $\$ 300$
SPECIAL FOURTH-CLASS RATE BOOK

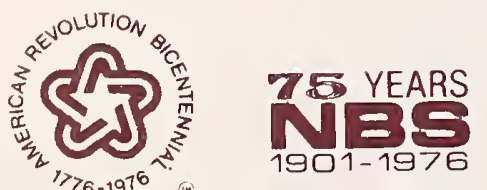

